\title{
Pre- and post-operative imaging of cochlear implants: a pictorial review
}

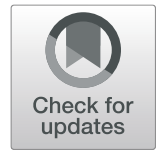

\author{
Gerlig Widmann ${ }^{1 *} \mathbb{D}$, Daniel Dejaco ${ }^{2}$, Anna Luger $^{1}$ and Joachim Schmutzhard ${ }^{2}$
}

\begin{abstract}
Cochlear implants are increasingly used to treat sensorineural hearing disorders in both children and adults. Preoperative computed tomography and magnetic resonance imaging play a pivotal role in patient selection, to rule out findings that preclude surgery or identify conditions which may have an impact on the surgical procedure. The post-operative position of the electrode array within the cochlea can be reliably identified using cone-beam computed tomography. Recognition of scalar dislocation, cochlear dislocation, electrode fold, and malposition of the electrode array may have important consequences for the patient such as revision surgery or adapted fitting.
\end{abstract}

Keywords: Cochlear implant, Pre-operative imaging, Post-operative imaging, Electrode array position

\section{Key points}

- Pre-operative imaging plays a pivotal role in patient selection for cochlear implant surgery.

- Key imaging findings on pre-operative scans that may have an impact on the surgical procedure need to be reported.

- Post-operative scans are indispensable to recognize dislocation, fold, and malposition of the electrode array, thereby allowing the best possible management of such a postsurgical complication.

\section{Introduction}

A cochlear implant (CI) is a surgically implanted device consisting of external and internal components [1]. An external microphone and speech processor are worn behind the ear and convert sound into an electric signal. A magnet held external transmitter sends the signal via electromagnetic induction through the skin to an internal receiver-stimulator. The receiver-stimulator converts the signal into rapid electrical impulses which are distributed to multiple electrodes on an electrode array implanted within the cochlea. The electrodes electrically

\footnotetext{
* Correspondence: gerlig.widmann@i-med.ac.at

${ }^{1}$ Department of Radiology, Medical University of Innsbruck, Anichstr. 35,

A-6020 Innsbruck, Austria

Full list of author information is available at the end of the article
}

stimulate the spiral ganglion cells along the cochlear turns, which then travel along the auditory nerve axons to the brain for sound perception. Straight lateral wall electrode arrays and pre-curved perimodiolar electrode arrays are available in different lengths for coverage of various cochlear duct lengths.

Over the past few decades, CI surgery has increased and revolutionized the treatment of severe to profound sensorineural hearing loss (SNHL) in both children and adults. In brief, current indications are (a) children (1224 months) with profound SNHL (>90 dB) and limited benefit from binaural amplification trial based on the meaningful auditory integration scale; (b) children (217 years) with severe to profound SNHL (> 70 dB) with limited benefit from binaural amplification defined by $\leq$ 20-20\% word recognition scores; and (c) adults with moderate to profound SNHL in both ears $(>40 \mathrm{~dB})$ with limited benefit from binaural amplification defined by $\leq$ $50 \%$ sentence recognition in the ear to be implanted (or $\leq 40 \%$ by centers for medicare and medicaid services criteria) and $\leq 60 \%$ in the contralateral ear or binaurally [ 1 , 2]. More recently, indications have been expanded to patients with single-sided deafness and ipsilateral vestibular schwannoma [2].

Absolute contraindications are complete labyrinthine aplasia, cochlear aplasia, and complete cochlear ossification. CI in cochlear nerve aplasia or hypoplasia is

\section{Springer Open}

(c) The Author(s). 2020 Open Access This article is licensed under a Creative Commons Attribution 4.0 International License, which permits use, sharing, adaptation, distribution and reproduction in any medium or format, as long as you give appropriate credit to the original author(s) and the source, provide a link to the Creative Commons licence, and indicate if changes were made. The images or other third party material in this article are included in the article's Creative Commons licence, unless indicated otherwise in a credit line to the material. If material is not included in the article's Creative Commons licence and your intended use is not permitted by statutory regulation or exceeds the permitted use, you will need to obtain permission directly from the copyright holder. To view a copy of this licence, visit http://creativecommons.org/licenses/by/4.0/. 
controversial. Patients are less likely to benefit, but meaningful hearing can be achieved in selected cases [3, 4]. In children with syndromic disorders such as CHARGE (congenital features of coloboma of the eye, heart defect, atresia of the nasal choanae, retardation of growth and/or development, genital and/or urinary abnormalities, and ear abnormalities and deafness), CI implant surgery is very challenging due to abnormal anatomy and comorbidity $[5,6]$. Disabilities including developmental delay, cerebral palsy, visual impairment, autism, and attention deficit disorder significantly affect the outcomes [7]. For elderly patients, general health problems and life expectancy should be taken into account, and the indications for CI should be considered on a case by case basis [8]. Acute infections such as otitis media and mastoiditis as well as chronic inflammation and cholesteatoma must be adequately controlled before CI surgery [9].

Radiologists play an essential role in the pre- and postoperative evaluation and selection of CI candidates. Preoperative imaging is essential to diagnose any type of inner ear malformations and to identify other abnormalities in the temporal bone that may be encountered [10, 11]. It allows the best insight into all relevant anatomical details and potential situations which preclude surgery or require modifying standard surgical approaches [12, 13]. Post-operative imaging is important to confirm and document the intended electrode position and to demonstrate any scalar dislocation, cochlear dislocation, electrode fold, or malposition, which can be a possible source of CI malfunction [14].

This pictorial review aims to provide a comprehensive overview of the most relevant pre-operative and postoperative imaging aspects in $\mathrm{CI}$ candidates intending to help radiologists and surgeons in routine practice.

\section{Pre-operative imaging Modalities and protocols}

Pre-operative imaging in CI candidates is based on highresolution computed tomography (HRCT) and magnetic resonance imaging (MRI) [15]. Practical generic imaging protocols are given in Table 1. Each modality has its strengths and both modalities are complementary to each other (Table 2) [15-17].

The strength of HRCT is the detailed visualization of the bony structures of the middle and inner ear. The cochlea is composed of the central modiolus with bony septa that separate the basal, middle, and apical turns (2.5-2.75 turns) (Fig. 1). Each turn contains the scala vestibuli, scala tympani, and the cochlea duct. All relevant anatomical structures including the middle ear, round and oval windows, vestibular aqueduct, segments of the facial nerve, and internal auditory canal are visualized. The length of the cochlear duct (CDL) or two-turn
Table $1 \mathrm{HRCT}$ and MRI protocols for pre-operative imaging and considerations in children

\begin{tabular}{ll}
\hline HRCT & MRI (3T preferred) \\
\hline 120-140 kVp, 100 mAs & T2w 2-mm-slice thickness, axial, \\
Helical scan, pitch 0.8-0.9 & and coronal orientation \\
FOV 15-16 cm & CISS-3D or vendor-specific \\
$0.5-0.6-\mathrm{mm}$-slice thickness & equivalent 0.8 slice thickness, \\
Sharp kernels, W/L: 4000/500 & axial orientation \\
Slice orientation: axial and coronal & T1w/T1WC+(contrast-enhanced) \\
& fat sat, 2-mm-slice thickness, axial \\
& orientation \\
& Non-EPI-DWI 2-mm-slice thickness, \\
& coronal orientation \\
& Contrast media: history of \\
& inflammation/infection \\
& Children \\
Children & Sedation/general anesthesia + \\
Sedation $+/-$ & Radiation dose - \\
Radiation dose + &
\end{tabular}

length (2TL) can be three-dimensionally segmented starting from the round window up to the apex or calculated using formulas (see Fig. 2) $[18,19]$.

Eight different types of cochlear malformations can be differentiated by HRCT: (1) complete labyrinthine aplasia-Michel deformity (complete absence of cochlea, vestibule, vestibular aqueduct, and cochlear aqueduct), (2) cochlear aplasia (absence of the cochlea), (3) rudimentary otocyst (incomplete millimetric otic capsule remnant), (4) common cavity (cochlea and vestibule are represented by a single chamber), (5) incomplete partition of the cochlea (defect in the modiolus and the interscalar septa with three subtypes), (6) cochlear hypoplasia (cochlea with dimensions less than normal with four subtypes), (7) large vestibular aqueduct syndrome (enlarged vestibular aqueduct in the presence of normal cochlea, vestibule, and semicircular canals), and (8) cochlear aperture abnormalities (narrow cochlear nerve canal or internal auditory canal, possibility of an absent, or hypoplastic cochlear nerve) [10].

The strength of the MRI is the visualization of the fluid content of the membraneous labyrinth (Fig. 3). Visualization of the vestibulocochlear nerve in the fluidfilled internal auditory canal and cerebellopontine angle is only possible by the MRI [16]. History of meningitis, temporal bone fracture, or otosclerosis may lead to cochlear fibrosis or scarring, which appear as a loss of fluid signal. Sclerosis of the cochlea can be seen in

Table 2 Comparison of CT and MRI in imaging of various preoperative conditions

\begin{tabular}{lcc}
\hline & CT & MRI \\
\hline Bone anatomy & + & - \\
Membranous labyrinth & - & + \\
Cochlear sclerosis & + & + \\
Cochlear fibrosis, inflammation & - & + \\
Cochlear nerve hypoplasia or aplasia & - & + \\
\hline
\end{tabular}



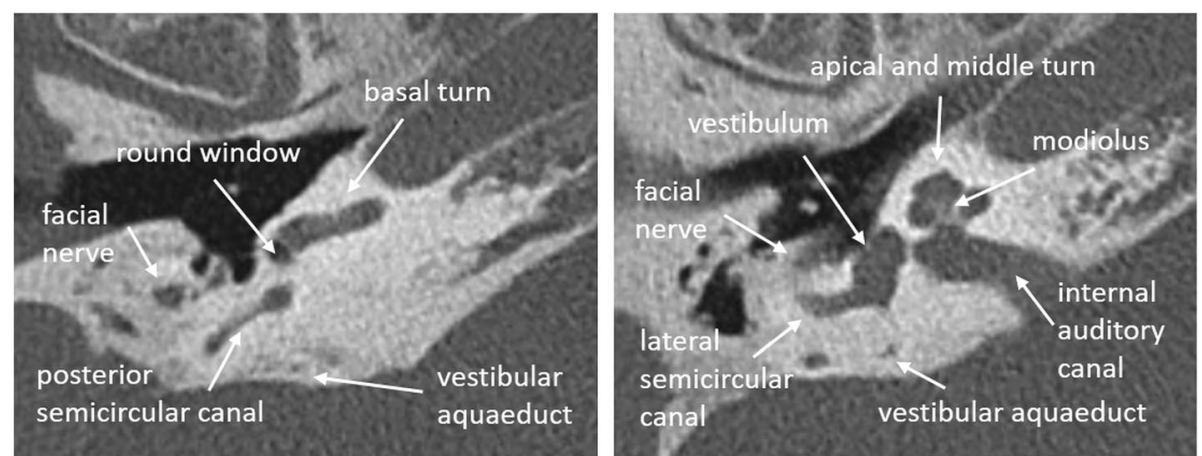

Fig. 1 HRCT axial images of normal cochlear anatomy in a 74-year-old man
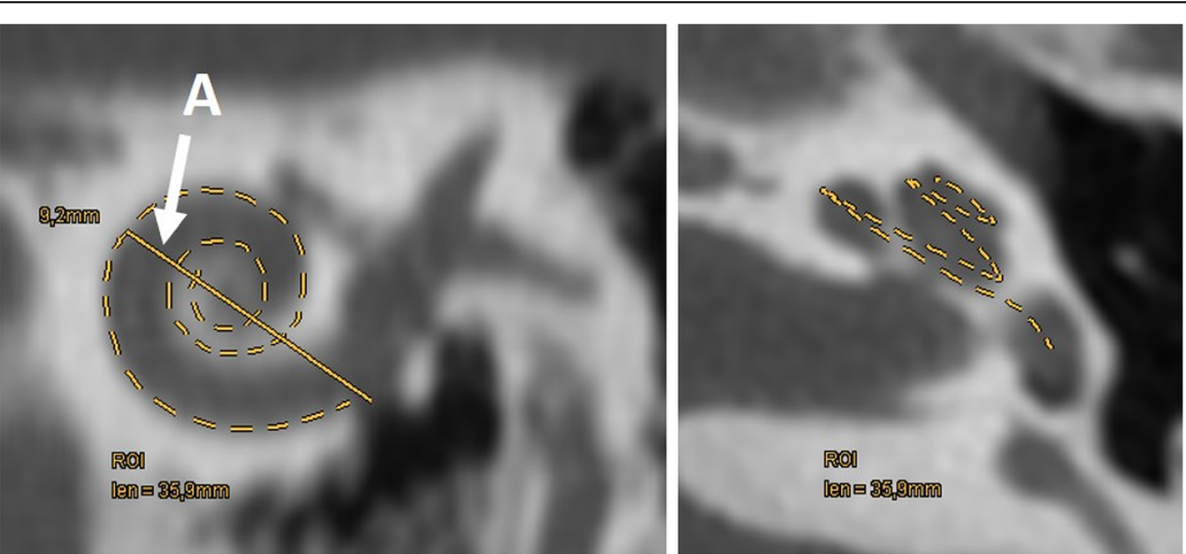

Fig. 2 Evaluation of cochlear duct length (CDL) using the formula $C D L=4.16 \mathrm{~A}-2.7$ and a 3D segmentation (dashed line). HRCT paracoronal image on the left shows distance A (arrow) from the center of the round window to the far most extension of the basal turn, which measures $9.2 \mathrm{~mm}$. According to the formula the cochlea duct has a length of $35.6 \mathrm{~mm}$. The dashed line in the HRCT paracoronal image and the HRCT paraaxial image on the right shows the 3D segmented cochlear duct which measures $35.9 \mathrm{~mm}$
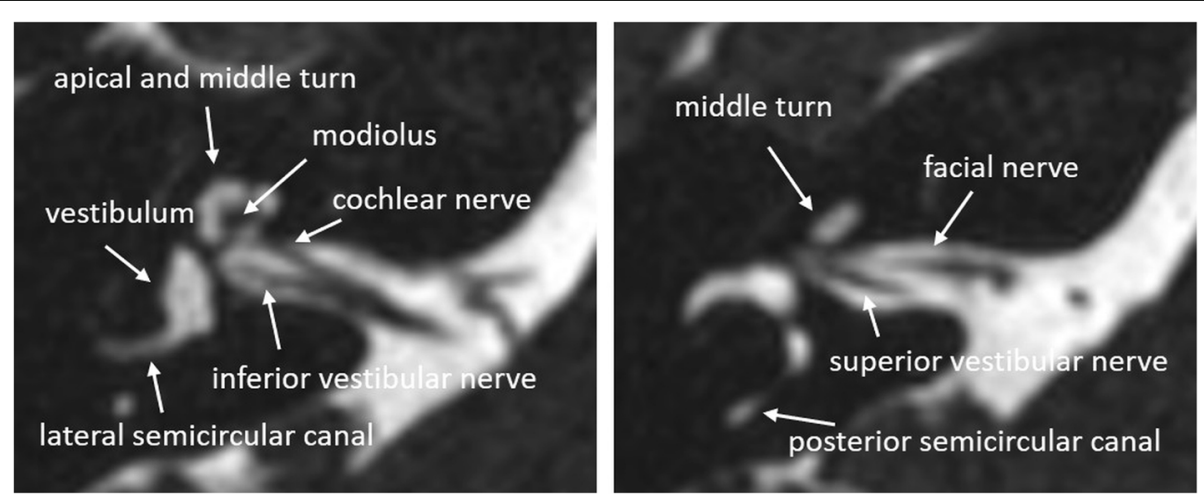

Fig. 3 MRI 3D-CISS axial images of normal cochlear anatomy in a 40-year-old woman 


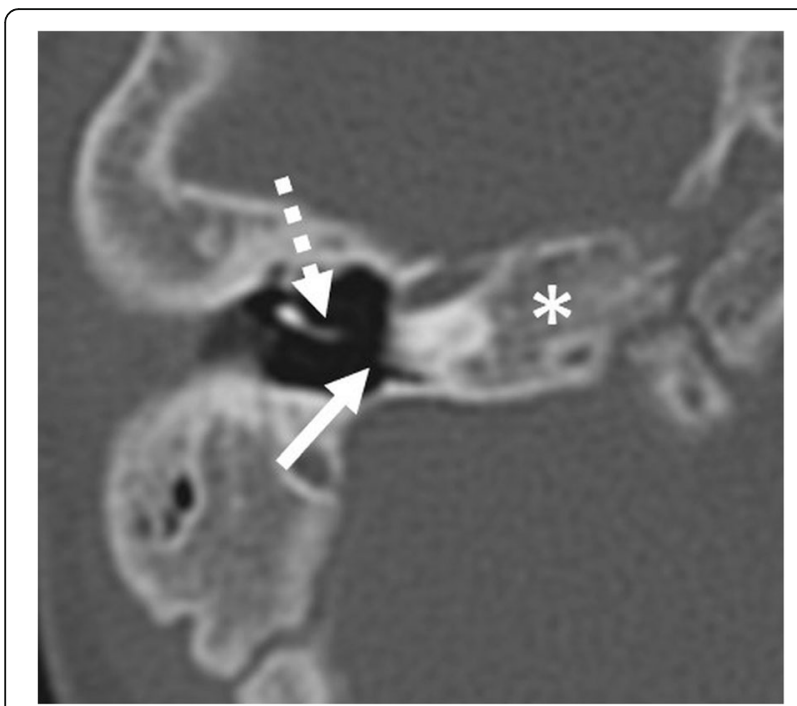

Fig. 4 A 1-year-old male patient, with bilateral sensorineural deafness from birth. HRCT axial image shows hypoplastic right petrous bone with a complete absence of the inner ear structures (asterisk), compatible with Michel's deformity. The medial wall of the middle ear is flat (arrow). Absent round and oval windows. Absent stapes. Normal-looking malleus (dashed arrow)

HRCT; however, early fibrotic stages may only be depicted by MRI [20]. Contrast enhancement may support the diagnosis of fibrosis and inflammation.

\section{Key imaging findings which preclude cochlear implantation}

The most commonly accepted imaging findings precluding cochlea implantation are [1]:
- Complete labyrinthine or isolated cochlear aplasia (Fig. 4)

- Cochlear sclerosis (Fig. 5)

- Cochlear nerve deficiency (Fig. 6)

\section{Key imaging findings which have an impact on the surgical procedure Common cavity malformation}

The common cavity is a malformation in which the cochlea and vestibule are represented by a single chamber [10]. It can be exceedingly difficult to place the electrode array close to the neural elements. Satisfactory clinical results are achieved when the stimulating electrode contacts form a loop within the cavity [21-23]. Modification of the cochleostomy shape and looping of the cochlear implant electrode in the implantable cystic space is recommended [22]. Custom-made devices for common cavities are available from some manufacturers [24].

\section{Cochlear hypoplasia (Fig. 7)}

Cochlear hypoplasia may appear as bud-like cochlea (type I), cystic hypoplastic cochlea (type II), cochlea with less than 2 turns (type III), and with normal basal turn, but severely hypoplastic middle and apical turns (type IV) [10]. Due to the small size of the hypoplastic cochlea, thin and short electrodes are recommended. Thick and long electrodes may not be fully inserted into the cochlea. The cystic hypoplastic cochlea has a potential for cerebrospinal fluid leakage [11].

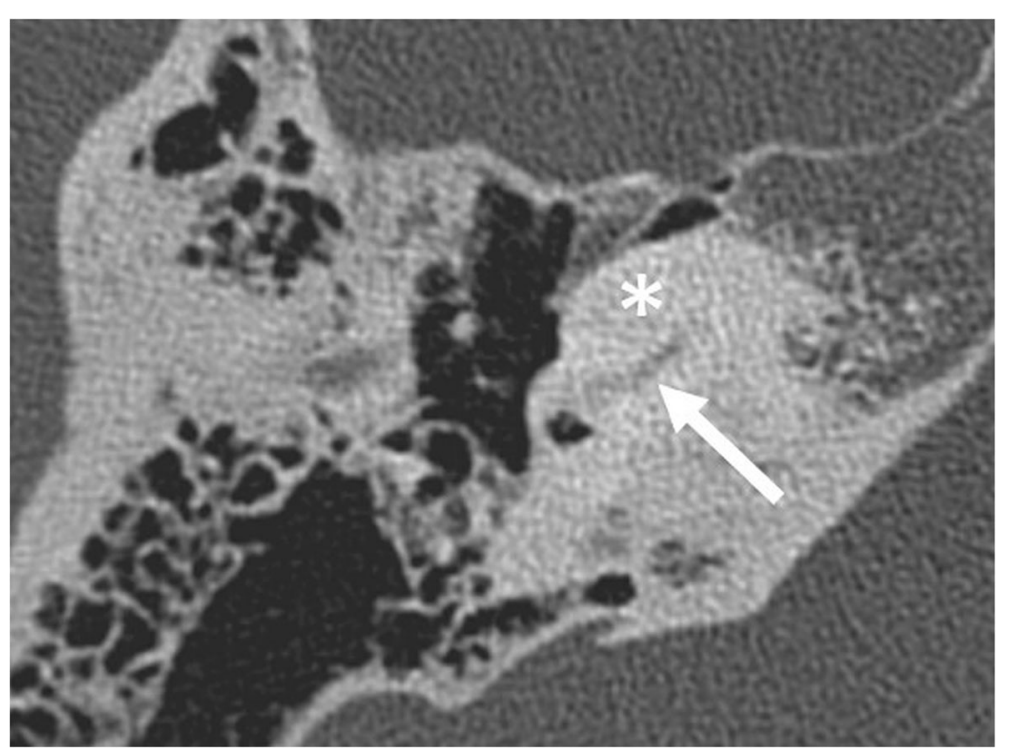

Fig. 5 A 38-year-old female patient, with unilateral sensorineural deafness since the age of 12 years. HRCT axial image shows cochlear sclerosis (asterisk). Only a small part of the basal turn of the cochlea can be faintly seen (arrow) 

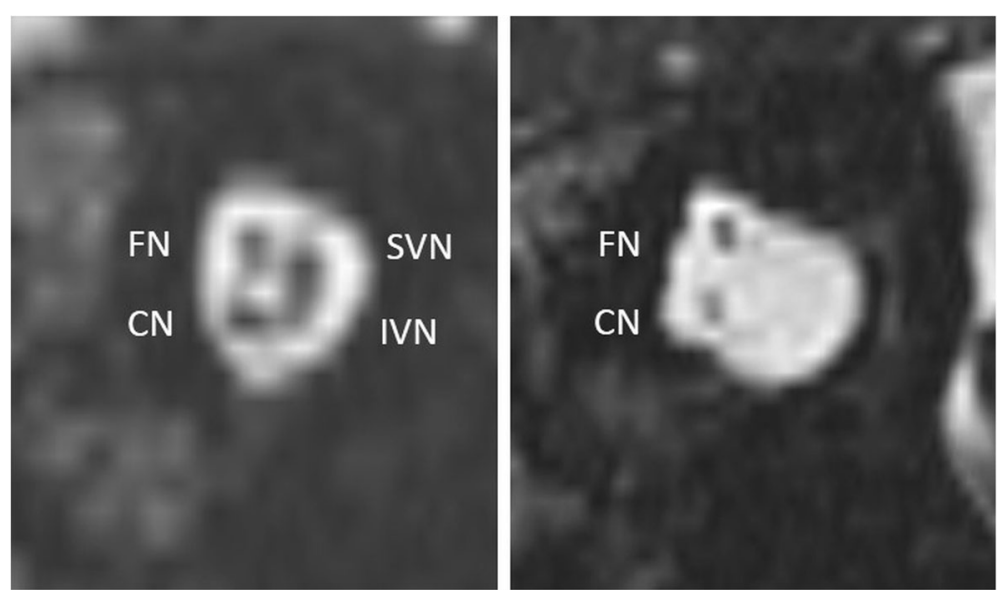

Fig. 6 A 57-year-old female patient with unilateral SNHL from birth. MRI 3D-CISS parasagittal image of the internal auditory canal shows regular facial nerve (FN), cochlear nerve (CN), superior vestibular nerve (SVN), and inferior vestibular nerve on the healthy side (left image) and missing SVN and IVN, as well as a hypoplastic CN on the diseased side (right image)

\section{Incomplete partition (Figs. 8, 9, and 10)}

Incomplete partition type I (Fig. 8) shows no modiolus and interscalar septa [10]. It looks like an empty cystic structure and is accompanied by a large dilated vestibulum. It can be challenging to place the electrode array close to the neural elements $[25,26]$. An aggressive attempt at the full insertion of the array may result in misplacement through the deficient modiolus into the internal auditory canal [26].

Incomplete partition type II (Fig. 9) shows a cystic apex of the cochlea and only the basal parts of the modiolus are present. In addition, the vestibular aqueduct is

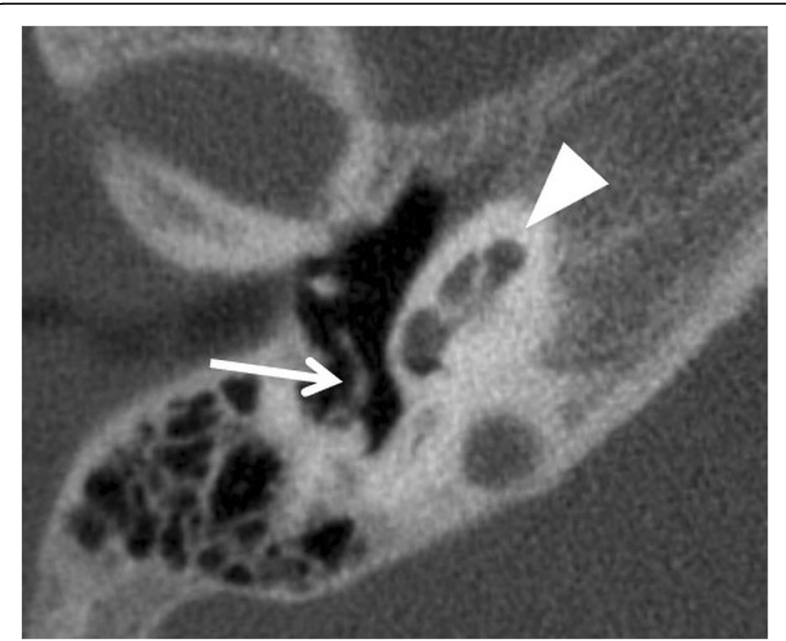

Fig. 7 A 5-year-old male patient, with CHARGE syndrome and bilateral severe SNHL from birth. HRCT axial image shows hypoplastic cochlea type III with less than 2 turns (arrowhead). Malformed crus longum incudis and stapes are fused with the posterior tympanic wall (arrow) enlarged, and the vestibule is minimally dilated. The full triad is named Mondini deformity [10].

Incomplete partition type III (Fig. 10) is reported in X-linked deafness [27]. The interscalar septa are present but the modiolus is completely absent. The cochlea is placed directly at the lateral end of the internal auditory canal instead of its usual anterolateral position. The missing bony separation of the cochlea and internal auditory carries an increased risk for an electrode dislocation into the internal auditory canal [28].

Modiolar base defects in incomplete partitions have increased risk of intraoperative cerebrospinal fluid leakage into the middle ear, named gusher [25, 29]. An intraoperative gusher is resulting in a prolonged procedure, hampers the electrode insertion, and increases the risk of meningitis. Tight cochleostomy and thoroughly packing with the tissue around the electrode array may be needed [14]. Dedicated electrodes with a cork stop like electrode design may improve the sealing of the electrode at the cochlear entry $[21,30]$.

\section{Large vestibular aqueduct syndrome (Fig. 11)}

This syndrome shows an enlarged vestibular aqueduct with the otherwise regular cochlea, vestibule, and semicircular canals [31, 32]. Cincinnati criteria (midpoint $>0.9 \mathrm{~mm}$ or operculum $>1.9 \mathrm{~mm}$ ) and the Valvassori criterion (midpoint $>$ or $=1.5 \mathrm{~mm}$ ) for enlarged vestibular aqueduct are used. Cincinnati criteria are found to be more sensitive to identify pediatric cochlear implant patients who might otherwise have no known etiology for their deafness [33]. The enlarged vestibular aqueduct results from an abnormal connection between the perilymphatic and 

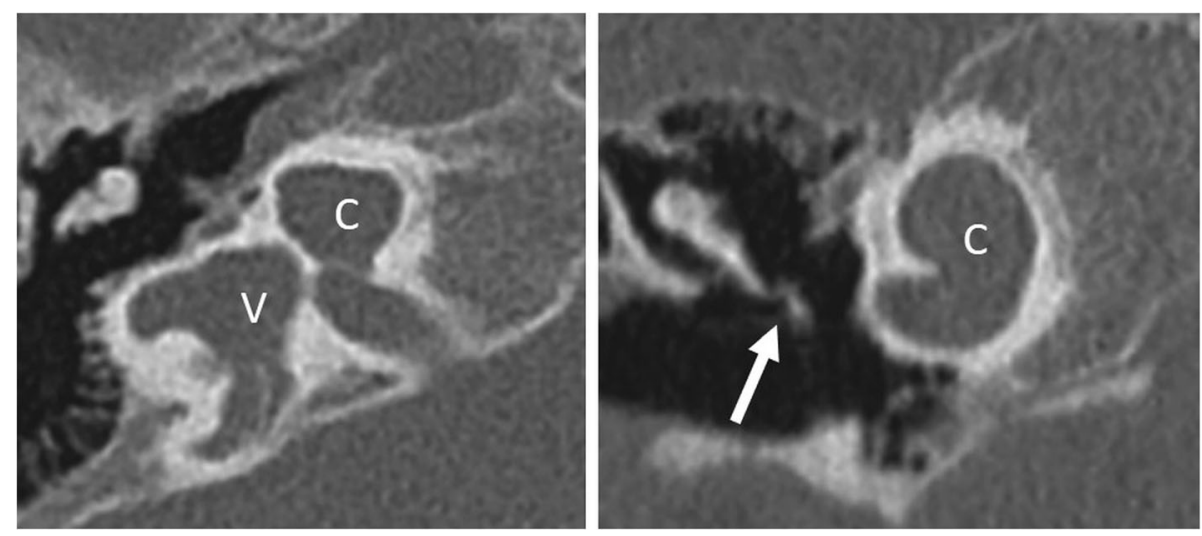

Fig. 8 A 1-year-old male patient, with sensorineural deafness from birth. HRCT axial image (left) and coronal image (right) show incomplete partition type I, with empty cystic cochlea (C) and a large dilated vestibulum (V). Stapes is malformed and fused with the incus (arrow)
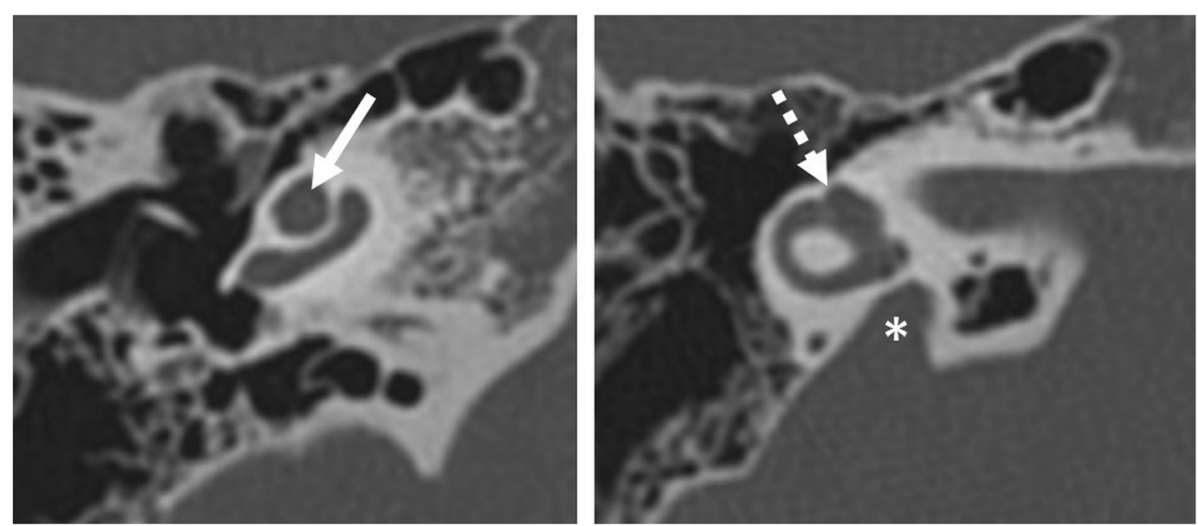

Fig. 9 A 12-year-old male patient, with bilateral severe SNLH from birth. HRCT axial images show incomplete partition type II with the cystic apex of the cochlea (arrow) and enlarged vestibular aqueduct (asterisk). Vestibulum is minimally enlarged (dashed arrow), and semicircular canals appear normal

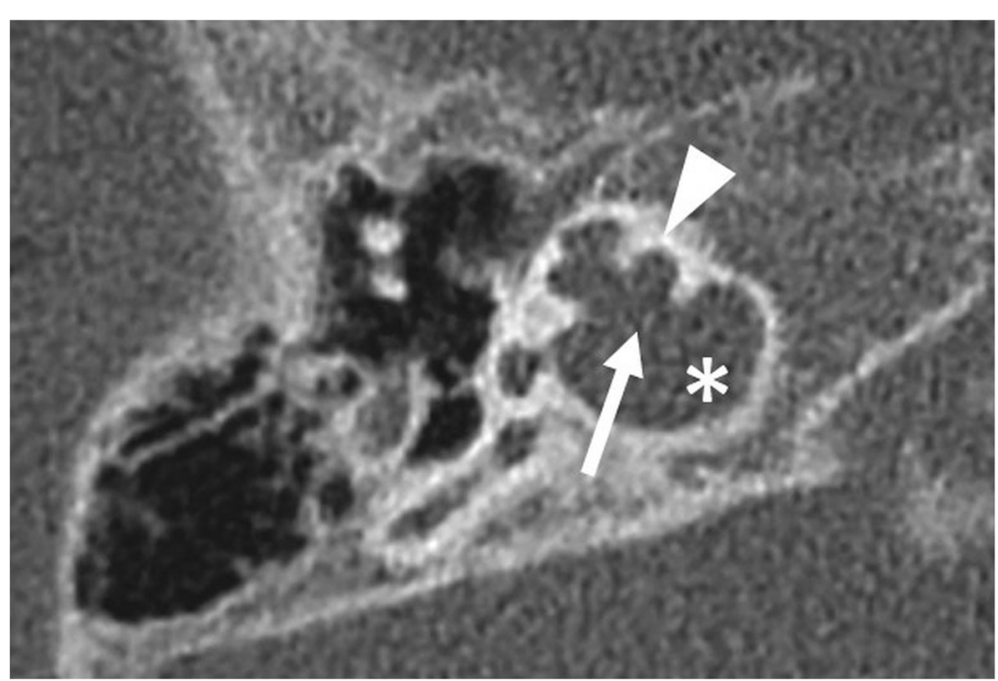

Fig. 10 A 1-year-old male patient, with bilateral severe SNLH from birth. HRCT axial image shows incomplete partition type III with empty cochlea with preserved interscalar septa (arrowhead). Modiolus and bony separation of the cochlea and internal auditory canal are absent (arrow). The cochlea is placed directly at the lateral end of the internal auditory canal (asterisk) 

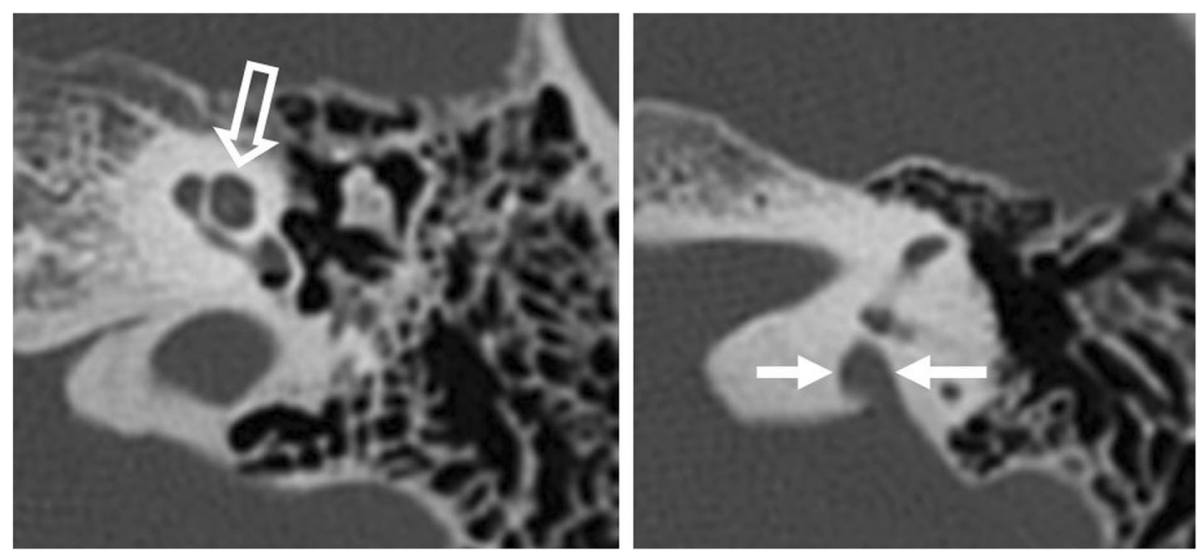

Fig. 11 A 56-year-old male patient, with bilateral severe SNLH from birth. HRCT axial images show regular cochlea (open arrow), regular vestibulum and semicircular canals (not shown), and enlarged bony opening for the vestibular aqueduct (arrows), compatible with large vestibular aqueduct syndrome

subarachnoid spaces, which transmits a high pressure into the cochlea. This condition may lead to an intraoperative gusher.

\section{Abnormal position of the facial nerve (Fig. 12)}

Malformations of the inner ear are frequently accompanied by abnormal positions of the facial nerve, which increases the risk of facial nerve palsy during surgery [34]. The labyrinthine segment of the facial nerve may show an anterior and superior displacement. The tympanic segment may be superiorly displaced, at the oval foramen, and inferiorly to the oval foramen. The mastoid segment may be lateralized and show a narrow facial recess. Modified surgical approaches such as retrofacial, trans-attic combined with transcanal, or facial recess combined with a transcanal approach are needed [35].
Hypoplastic round window or oval window (Fig. 13)

If the cochlear windows cannot be identified, it is very difficult to localize the cochlea for the correct cochleostomy site [5]. A CT-guided approach using a navigation system may be recommended to facilitate surgical orientation [12, 36]. Furthermore, deeply located narrow round windows may provide an awkward angle, which makes it difficult to insert the CI.

\section{Cochlear aperture abnormalities (Fig. 14)}

Cochlear nerve canal hypoplasia is defined by stenosis of the bony cochlear nerve canal diameter at the midmodiolus of $1.5 \mathrm{~mm}$ or less [37]. In about one third of cases of stenotic bony cochlear nerve canal, there is also a stenotic internal auditory canal with a diameter at the midpoint of the canal smaller than $2.5 \mathrm{~mm}$. These patients frequently show a hypoplastic or aplastic cochlear nerve, which impedes clinical outcomes [38]. Hypoplasia
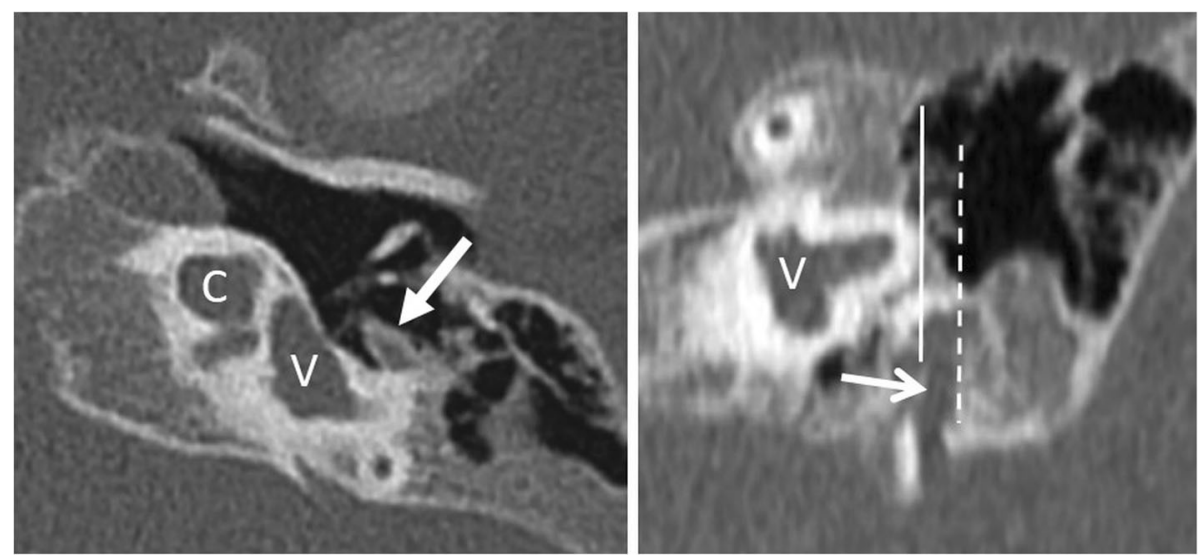

Fig. 12 A 1-year-old male patient, with bilateral severe SNHL from birth. HRCT axial image (left image) shows incomplete partition type I with cystic cochlea (C) and vestibulum ( $\mathrm{V}$. The horizontal segment of the facial nerve (arrow) is lateralized. HRCT coronal image (right image) shows an interrupted line corresponding to the most lateral aspect of the vertical segment of the facial nerve (open arrow) lateral to the continuous line corresponding to the most lateral bony aspect of the lateral semicircular canal. The normal location of the vertical segment is medial to the lateral semicircular canal 


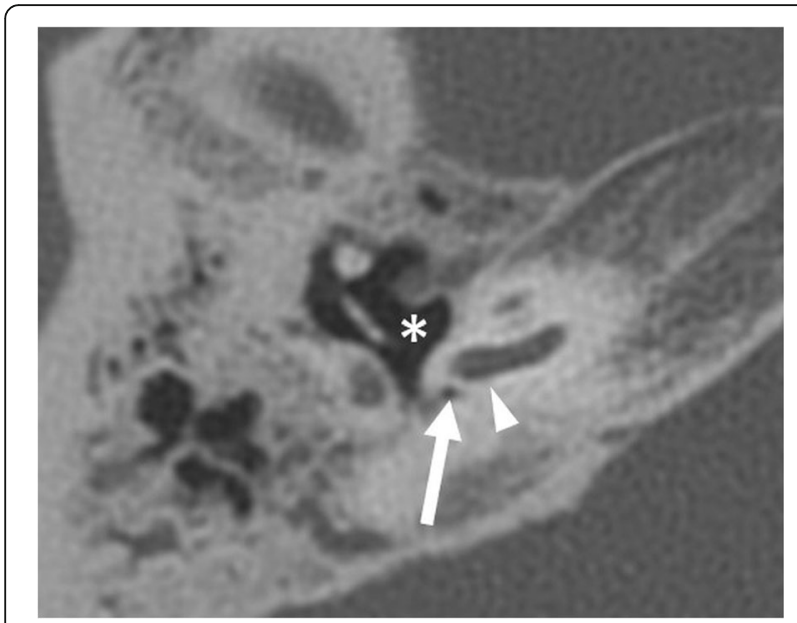

Fig. 13 A 65-year-old male patient, with external auditory canal hypoplasia and bilateral SNLH from birth. HRCT axial image shows a hypoplastic round window (arrow) and a small tympanic cavity (asterisk). This condition complicates anatomical orientation and surgical access to the basal turn (arrowhead)

of the vestibulocochlear nerve may be seen in cochlear aplasia, complete aplasia of the semicircular canals, severe cochlear hypoplasia, common cavity, incomplete partition type 1 , and mild cochlear hypoplasia, with decreasing degrees of correlation [39].

\section{Cochlear fibrosis (Fig. 15)}

Chronic otitis media, temporal bone fractures, meningitis, and Cogan's syndrome may lead to cochlear fibrosis [40]. In some cases, no obvious cause can be found. Even without evidence of sclerosis in CT, dense fibrotic tissue may pose a significant problem as the electrode may not be inserted into the cochlea. Surgical modifications including subtotal petrosectomy, split electrode arrays, and inverse approaches can be valuable options [36].

\section{Otosclerosis (Fig. 16)}

Far advanced otosclerosis may show irregular ossifications affecting the cochlea, which prevent regular entry and insertion of the CI. Split electrode arrays and inverse approaches can be successful [36].

\section{Chronic otitis media and cholesteatoma (Fig. 17)}

Identification of a chronic otitis media with or without cholesteatoma is important to prevent infection of the labyrinth during surgery [41]. Either a single-stage surgery with myringoplasty and thereafter the cochlear implantation is performed in the same procedure, or a more than one-staged surgery-firstly eliminating any disease, performing a myringoplasty or tympanoplasty and then performing the cochlear implantation 3-6 months later-is required. Such patients carry a mildly increased risk of device explantation, particularly in open cavity procedures [42].

\section{Post-operative imaging}

Modalities and protocols used to assess cochlear implants Post-operative imaging is required when a malfunction of the device is suspected [43]. However, the authors perform-and recommend to do so-a post-

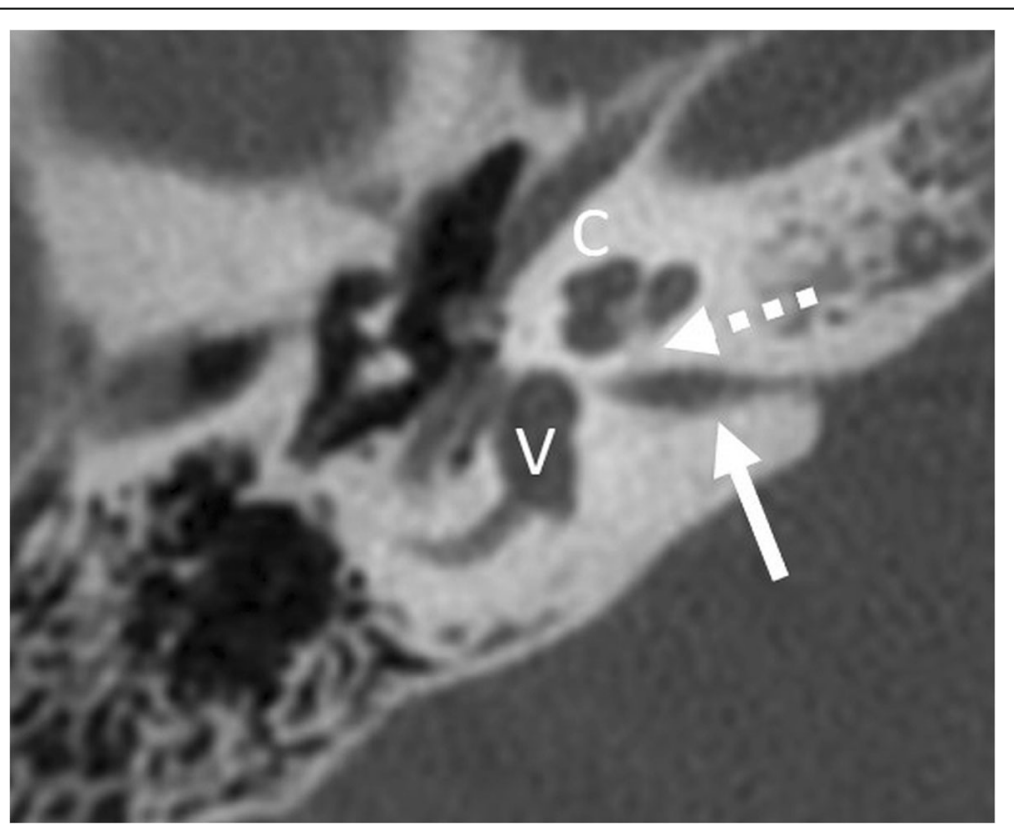

Fig. 14 A 16-year-old female patient, with unilateral deafness from birth. HRCT axial image shows high-grade stenotic bony cochlear nerve canal (dashed arrow) and the stenotic internal auditory canal (arrow). Cochlea (C) and vestibulum (V) appear normal 

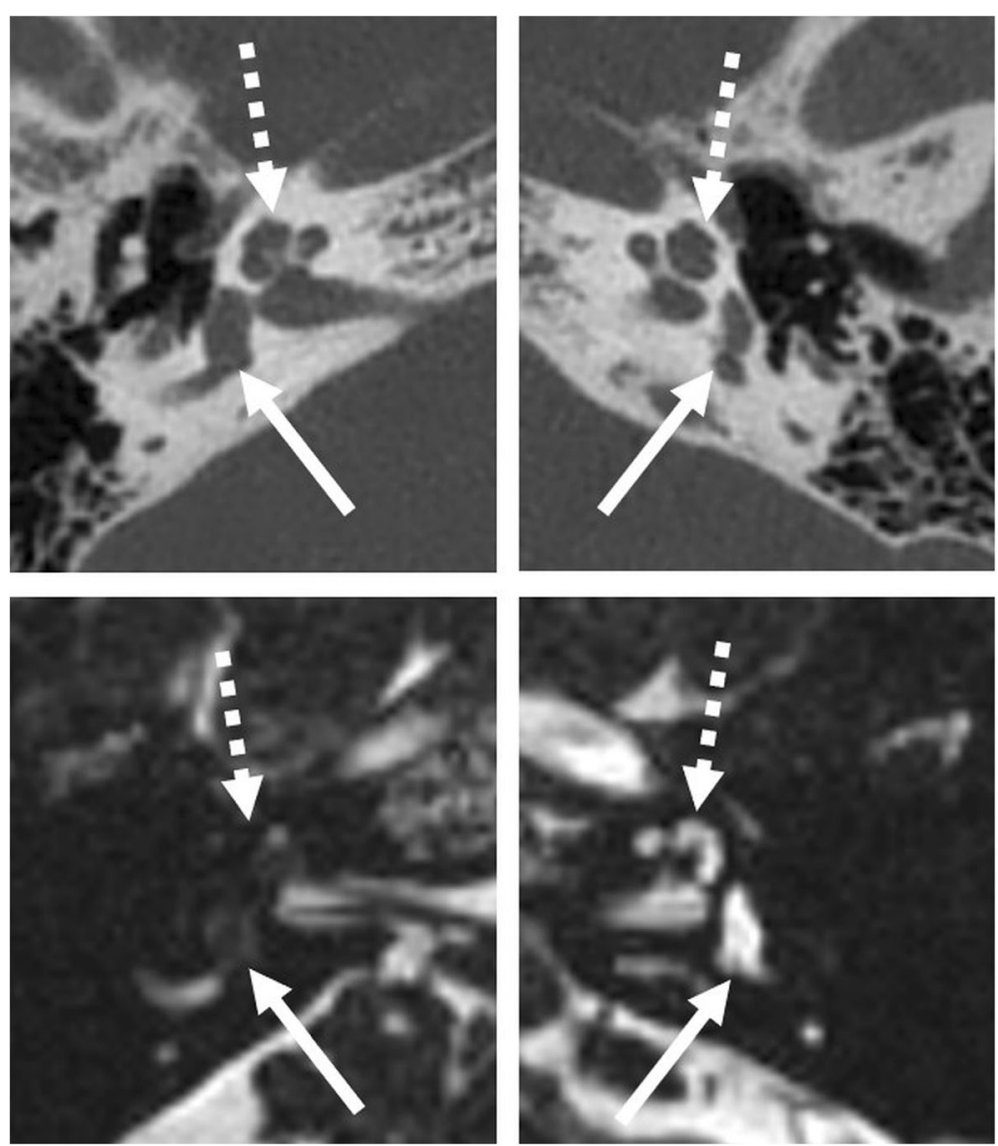

Fig. 15 A 51-year-old male patient, with unilateral SNHL from several years. HRCT axial images (upper image) shows normal bony cochlea (dashed arrow) and vestibulum (arrow) on both sides. However, MRI 3D-CISS axial images (lower images) show loss of signal intensity of the right cochlea (dashed arrow) and vestibulum (arrow), compatible with fibrosis in early-stage labyrinthitis ossificans

operative examination in every patient to confirm the correct position of the implant electrode. Information regarding basal electrode location helps improving programming accuracy, associated frequency allocation, and audibility with appropriate deactivation of extracochlear electrodes [44].
The post-operative position of the electrode array is evaluated using HRCT (similar protocol as for preoperative imaging) or cone-beam computed tomography (CBCT) (Fig. 18). CBCT has a higher spatial resolution but the performance of different models of $\mathrm{CBCT}$ may vary. In general, $\mathrm{CBCT}$ is associated with lower dose and

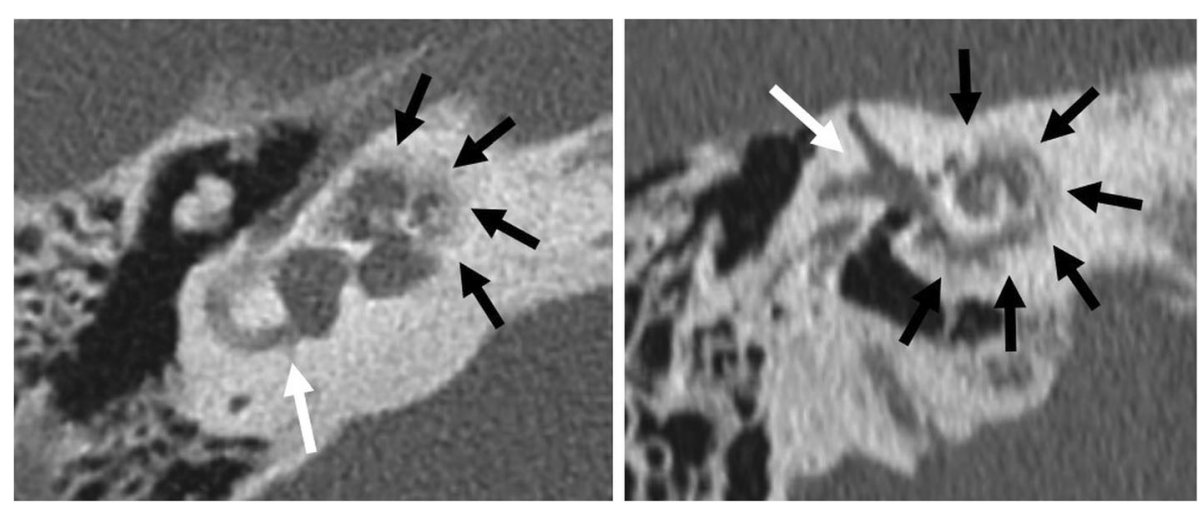

Fig. 16 A 70-year-old male patient, with progressive SNHL from advanced otosclerosis. HRCT axial (left image) and paracoronal (right image) image show irregular ossifications affecting the cochlea (black arrows). Vestibulum and semicircular canals (white arrows) are not affected 

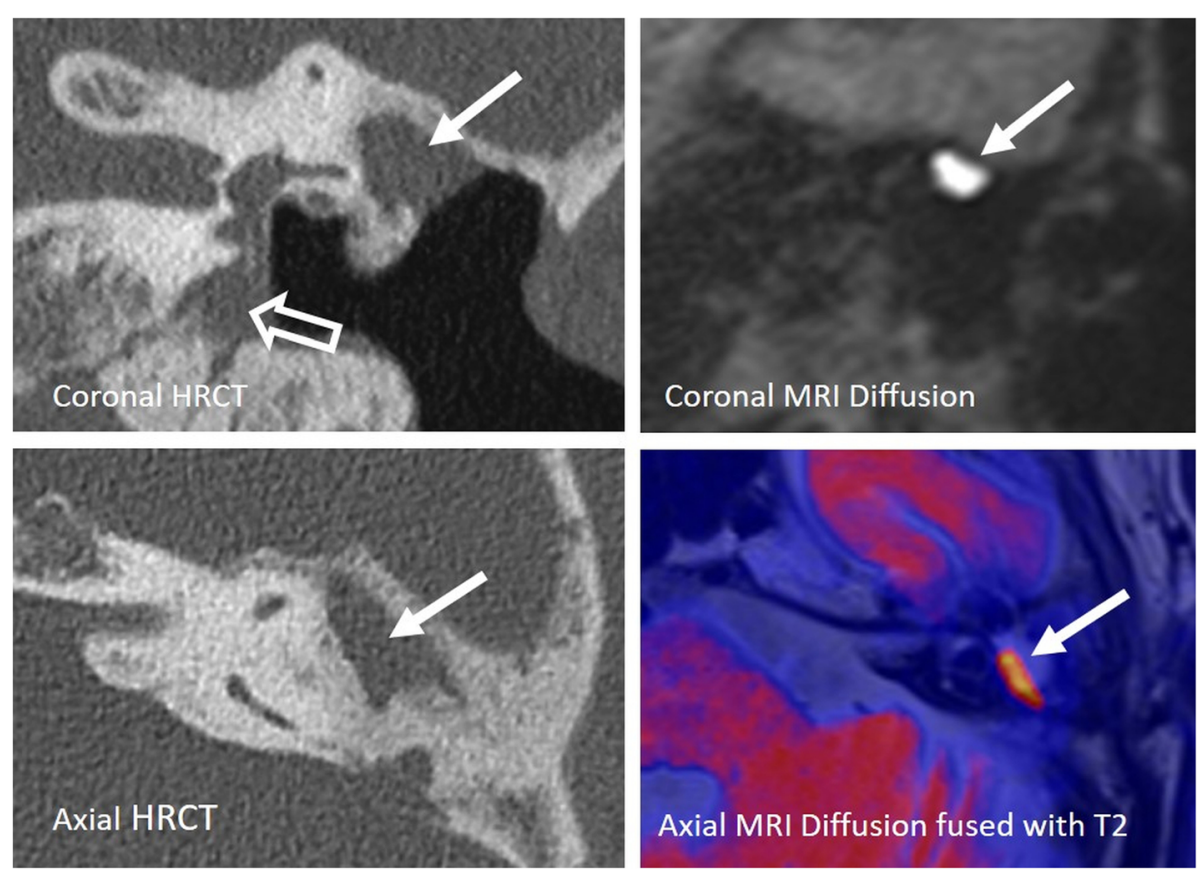

Fig. 17 A 80-year-old male patient, with severe SNHL enrolled for cochlear implant surgery. The patient had chronic middle ear infections and cholesteatoma surgery with tympanoplasty type IV several years ago. HRCT coronal and axial images (left images) show opacified antrum (arrow) and opacified hypotympanon (open arrow). A recurrent cholesteatoma cannot be ruled out. Corresponding MRI diffusion coronal image and color-coded axial image fused with T2 (right images) show a high signal intensity in the opacified antrum, typical for cholesteatoma (arrow). The diagnosis was surgically verified, and the patient successfully received a $\mathrm{Cl}$ one month after revision surgery

less metal artifacts when compared to HRCT (see Table 3 and Fig. 18) [45]. The scalar location of the electrode array can be identified by $\mathrm{CBCT}$ with a sensitivity of $100 \%$ and specificity of $90 \%$ [46]. The last generation CT scanners have significant dose saving options and provide iterative reconstructions for metal artifact reduction, which may reduce differences between both modalities $[47,48]$. Conventional X-rays including Stenvers projection cannot inform about the scalar location and may be difficult to interpret, especially in the case of malposition [49].

The visibility of the electrode array depends on the size and spacing of electrode contacts. An extensive
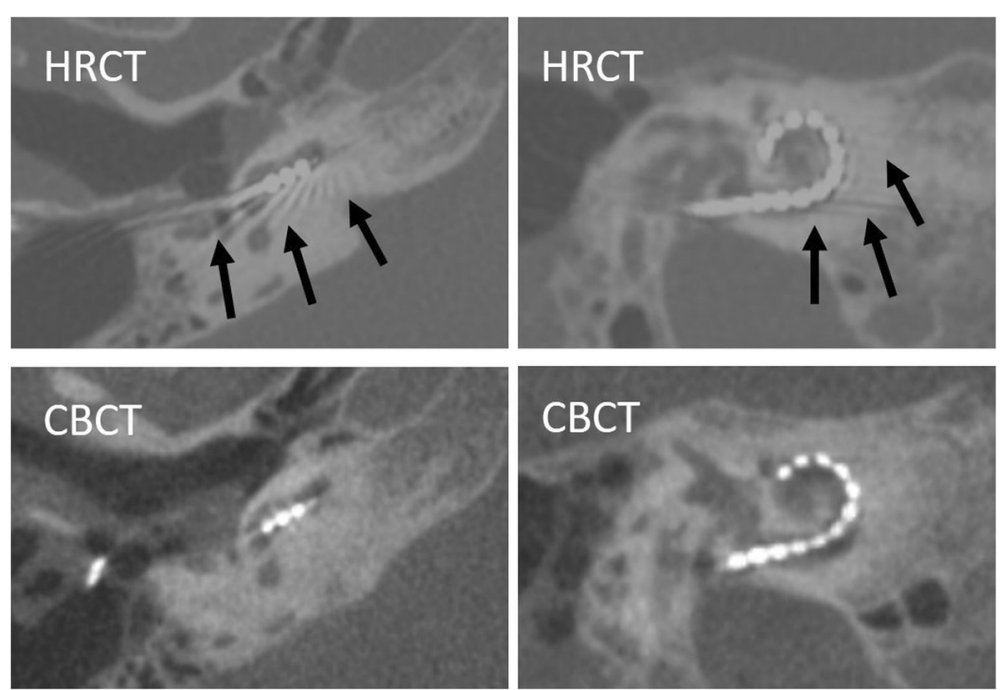

Fig. 18 Comparison of postoperative HRCT and CBCT in a 53-year-old female patient. Axial (left images) and paracoronal (right images) images. HRCT images show more metal artifacts (arrows) and blooming artifacts than CBCT images. However, the scalar location and number of electrode contacts can be reliably documented in both modalities 
Table 3 Comparison of HRCT and CBCT in evaluation of cochlea implants

\begin{tabular}{lll}
\hline & HRCT & CBCT \\
\hline Radiation dose & + & $+/-$ \\
Metal artifacts & + & - \\
Electrode contacts & $+/-$ & + \\
Scalar localization & $+/-$ & + \\
\hline
\end{tabular}

overview of the cochlear implant electrode array designs from different manufacturers can be found in the article by Dhanasingh et al. [21]. For optimal evaluation of the electrode, a paraxial mid-modiolar plane is selected using multiplanar reconstructions (Fig. 19). Maximum intensity projections with variable slice thickness can be used for the entire visualization of the electrode array. The insertion depth of the cochlear implant can be given as the radial position of the tip ranging from $45^{\circ}$ to a theoretical maximum of $900^{\circ}$ (full two and a half turns) [50].

\section{Normal post-operative imaging findings \\ Regular electrode (Fig. 20)}

Depending on the anatomical situation, the electrode array is inserted into the cochlea via three routes: (a) round window (preferred), (b) extended round window-enlarging and then opening the round window by drilling the anterior-inferior margin, and (c) cochleostomy-surgical opening of the cochlea [51]. The electrode array is intended to be placed in the scala tympani with close contact to the organ of Corti $[1,52]$. This placement may provide the best audiologic outcomes with an excellent speech perception and high rates of hearing preservation [53]. Depending on the type of implant and length of the cochlea, the location of the first electrode contact may be located $3-4 \mathrm{~mm}$ from the round window opening [21]. Periomodiolar electrode arrays may be located more closely to the modiolus than straight lateral wall electrodes.

\section{Split electrode (Fig. 21)}

Split electrodes are two electrodes which are independently implanted in the basal and the second cochlear turns. Such an approach may be needed in patients with a cochlea ossification/fibrosis and in far-advanced otosclerosis [36, 54].

\section{Retrograde electrode (Fig. 22)}

Postmeningitic basal turn ossification and fibrosis may block successful antegrade cochlear implantation despite the availability of sophisticated implants and advanced drill-out procedures. In such a case, a retrograde electrode insertion through a cochleostomy near the apex can be performed [55].

\section{Unfavorable positions and immediate complications}

Complications from cochlear electrode insertion are related to the degree of damage to the organ of Corti located at the basilar membrane and damage of neuronal structures at the spiral lamina [56]. Histological evaluation classifies different grades of electrode-induced trauma: lifting of the basilar membrane (grade 1), damage of the spiral ligament (grade 2), electrode translocation from the scala tympani to the scala vestibuli (grade 3 ), and fracture of the osseous spiral lamina or modiolus (grade 4) [57].

\section{Lifting of the basilar membrane (Fig. 23)}

An electrode array located in an intermediate position close to the midline of the cochlear lumen elevates the basilar membrane and bends or deforms the spiral ligament (grade 1 trauma) [58, 59]. It is more frequently observed using lateral wall electrodes compared with perimodiolar electrodes [60]. Damage to both the lateral cochlea wall and osseous
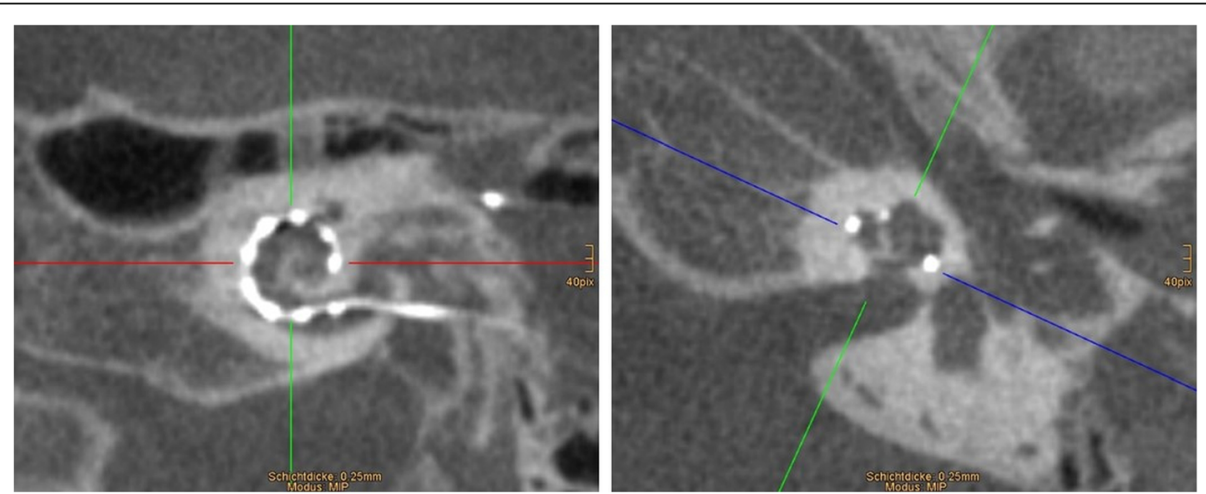

Fig. 19 Postoperative evaluation of cochlear implant location using multiplanar mid-modiolar reconstructions. CBCT paracoronal reconstruction at the basal turn (left image) and paraaxial reconstruction through the modiolus (right image). Maximum intensity projections may be used to visualize the entire electrode array 

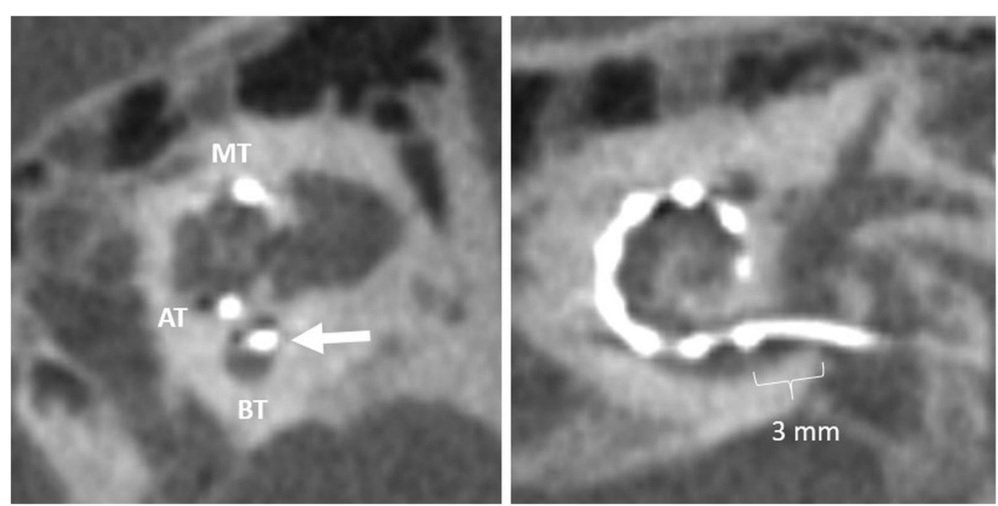

Fig. 20 A 15-year-old male patient, with normal postoperative finding after $\mathrm{Cl}$ surgery. CBCT paracoronal image (left image) shows an electrode array located in the scala tympani (lower segment) of the cochlear duct (white arrow). BT - basal turn. MT - middle turn. AT - apical turn. CBCT paraaxial image (right image) shows the most basal electrode contact for this type of implant correctly located $3 \mathrm{~mm}$ below the round window
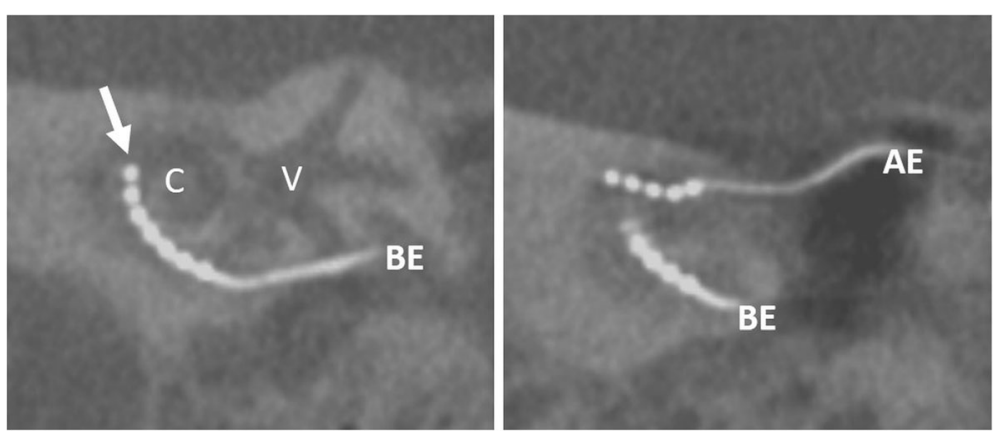

Fig. 21 A 70-year-old male patient, with normal postoperative finding after split electrode surgery due to far advanced otosclerosis. CBCT paracoronal image (left) shows basal electrode (BE) with the tip up to the first half of the basal turn (arrow). CBCT paraaxial maximum intensity projection image shows the additional apical electrode (AE) in the middle turn. C - cochlea. V - vestibulum
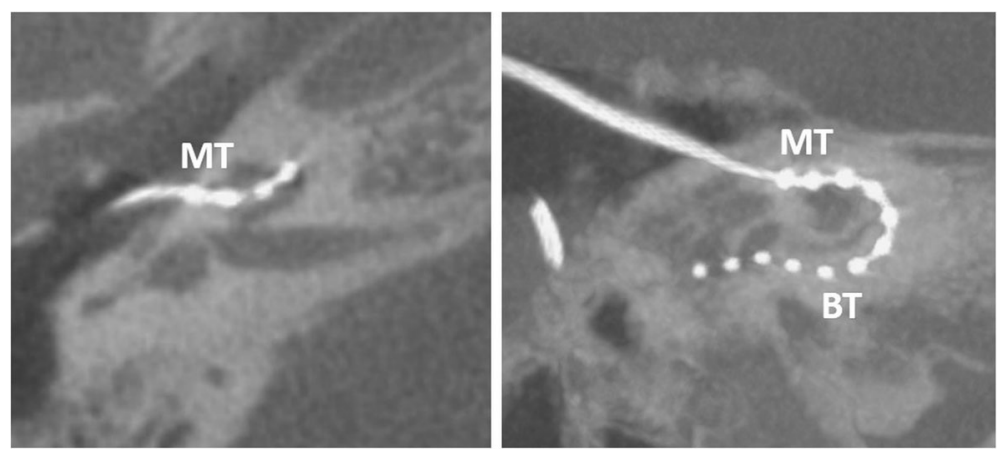

Fig. 22 A 51-year-old male patient, with normal postoperative finding after retrograde electrode surgery due to cochlear fibrosis. CBCT axial image (left image) shows electrode entering at the middle turn (MT). CBCT paraaxial maximum intensity projection image (right image) shows the electrode running down the basal turn (BT). The two most distal electrode contacts are in the tympanic space and need to be deactivated 


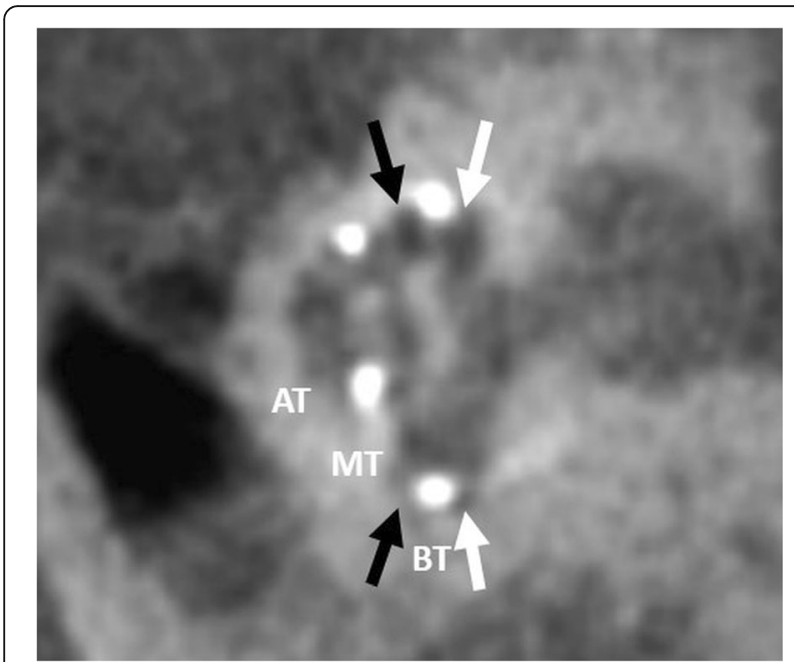

Fig. 23 A 72-year-old male patient, with electrode lifting the basilar membrane. CBCT paracoronal image shows the electrode array located in a lateralized and elevated intermediate position between scala vestibuli (black arrow) and scala tympani (white arrow). BT basal turn. MT - middle turn. AT - apical turn

spiral lamina tend to cause the new bone formation and fibrous tissue within scala tympani, which may result in a later reduction of the hearing performance [61].

\section{Scala vestibuli (Fig. 24)}

An electrode array placed in the scala vestibuli is more frequently seen after a cochleostomy approach [53]. This condition may show an increased risk of damage to

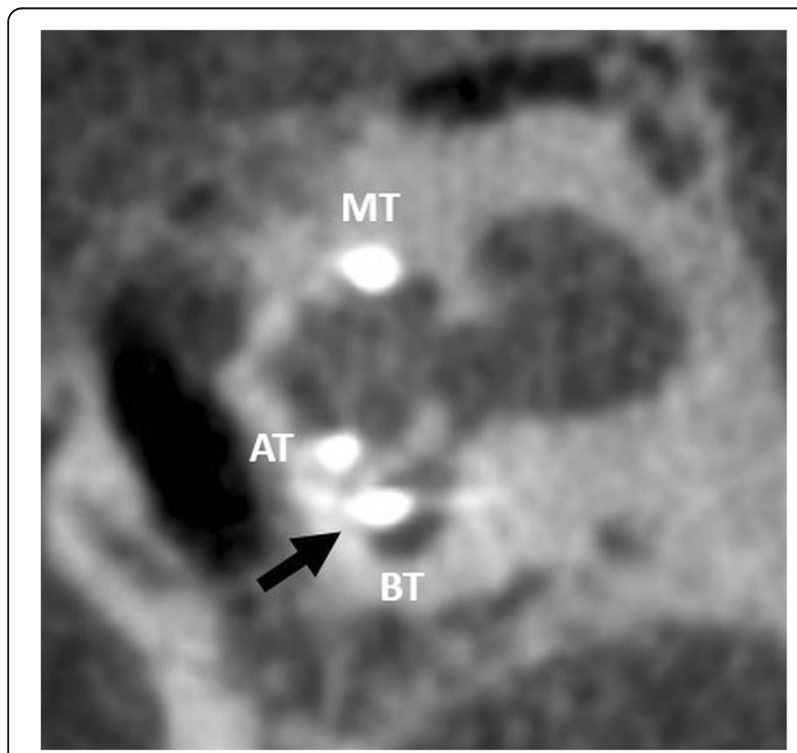

Fig. 24 A 70-year-old female patient, with an electrode placed in the scala vestibuli. CBCT paracoronal image shows an electrode array located in the scala vestibuli (upper segment) of the cochlear duct (black arrow). BT - basal turn. MT - middle turn. AT - apical turn sensorineural structures and spiral ganglia which may result in a less favorable outcome.

\section{Scalar translocation (Fig. 25)}

Electrode array translocation from scala tympani into scala vestibuli may be seen in $>20 \%$ and is more frequently observed when pre-curved electrodes are used [50, 62, 63]. Translocation usually occurs at $45-180^{\circ}$ insertion depth. It leads to a basilar membrane injury which may induce hearing loss. In a retrospective analysis of 63 patients, scalar translocation has been associated with an increase of the necessary stimulus charge [50].

\section{Overinsertion (Fig. 26)}

An overinserted electrode array can be recognized when the most proximal contact of the electrode is located more than 3-4 $\mathrm{mm}$ from the round window/cochleostomy. This may occur when the opening of the round window or cochleostomy is too large and the electrode is pushed too far into the cochlea. Clinical consequences can be reduced stimulation of the high frequencies, which may result in a poorer speech understanding [21].

\section{Underinsertion (Fig. 27)}

An underinserted electrode array exposes several contacts of the electrode array outside of the cochlea. The electrode array has been chosen too long or extruded contacts were a clinical compromise. Risk factors are otosclerosis, meningitis, chronic otitis media, temporal bone fractures, and neurofibromatosis-2 [64]. Underinsertion may result in a functional impairment because the external electrode contacts will not be able to stimulate the spiral ganglion cells. If revision surgery is needed, it should be performed within days, before healing and scaring processes have set in, for easier accessibility.

\section{Electrode pinching (Fig. 28)}

When the electrode array is inserted with too much force or cannot pass further into the cochlea duct, a bending or a more severe accordion-like pinching of the electrode array may be observed [36, 65]. The more severe the bending, the more likely is a mechanical damage of the electrode array. If electrodes overlap, they need to be deactivated.

\section{Tip fold-over (Fig. 29)}

Tip fold-over may have an occurrence rate of $1.5 \%$ and usually occurs with flexible and slim perimodiolar electrodes $[63,66,67]$. Fold-over in the cochlea may lead to the rupture of the basilar membrane. Overlapping electrode contacts may need to be deactivated [68]. This may improve performance and avoid revision surgery. 

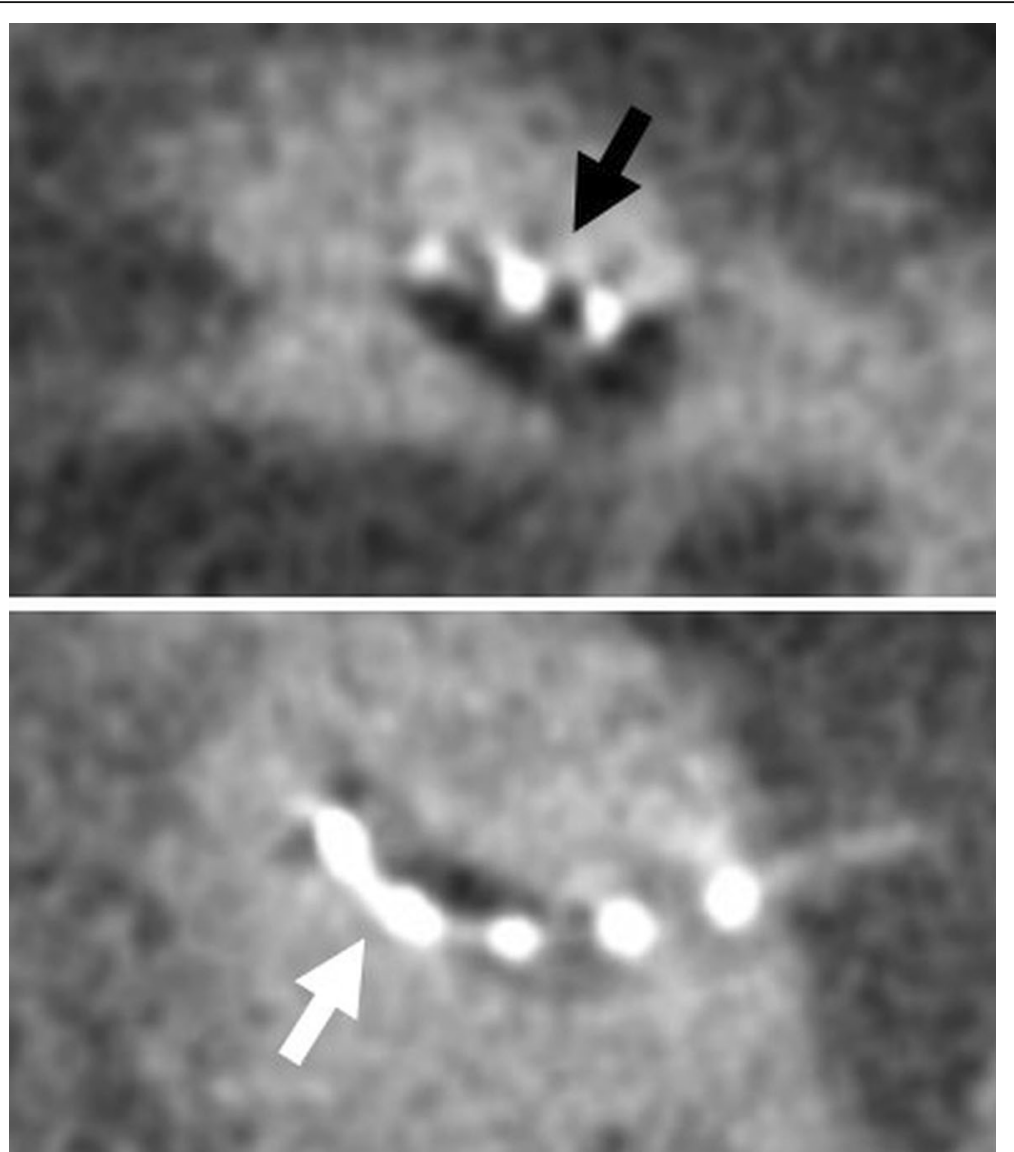

Fig. 25 A 62-year-old male patient, with the scalar translocated electrode. CBCT axial images show translocation of the electrode array from scala tympani (white arrow) into scala vestibuli (black arrow). The electrode was inserted via cochleostomy

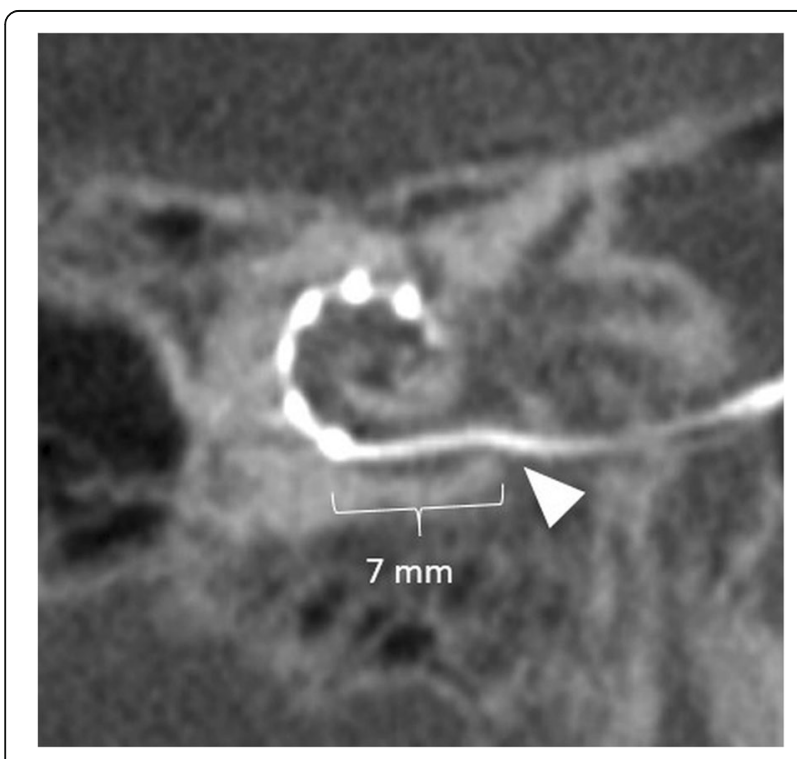

Fig. 26 A 11-year-old male patient, with overinserted electrode. $\mathrm{CBCT}$ paraaxial maximum intensity projection image shows the most basal electrode contact $7 \mathrm{~mm}$ from the round window (arrowhead)

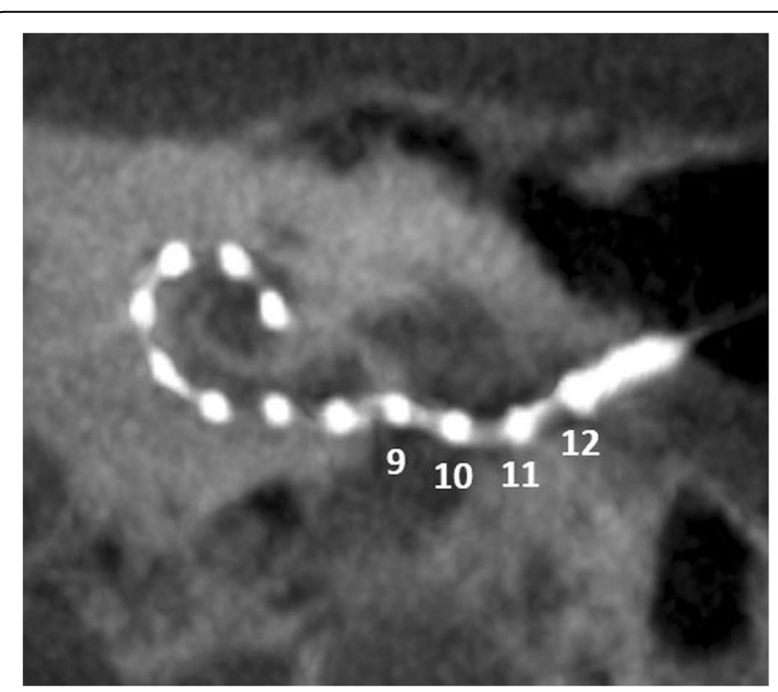

Fig. 27 A 66-year-old female patient, with underinserted electrode. CBCT paraaxial maximum intensity projection image shows extracochlear location of electrode contacts 9 to 12 

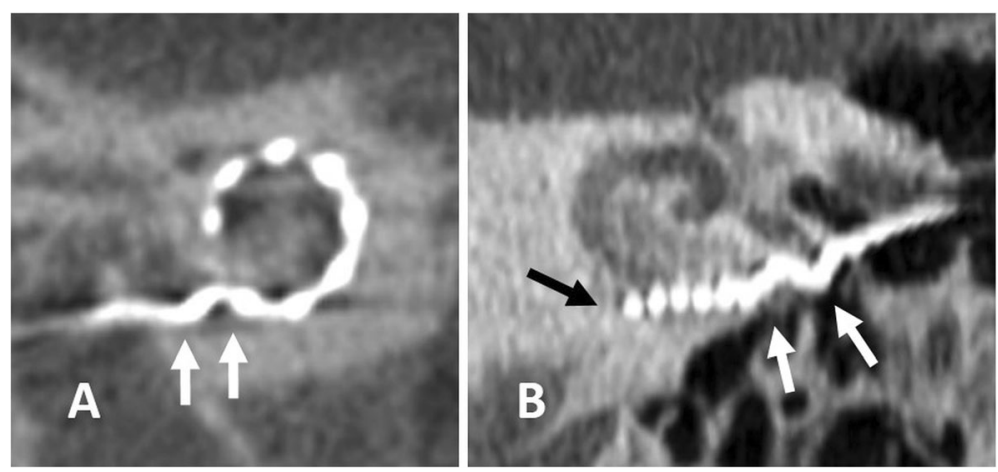

Fig. 28. a A 75-year-old female patient, with electrode bending. CBCT paraaxial image shows electrode bending (arrows) at the basal turn. b A 70-year-old male patient with electrode pinching in far advanced otosclerosis. CBCT paraaxial image shows accordion-like pinching of the basal parts of the electrode array (white arrows). The tip of the electrode array sticks at the basal turn and does not turn around the modiolus (black arrow)

\section{Basal fold-over (Fig. 30)}

When the electrode array cannot be fully inserted, excessive pushing may result in a fold-over of the basal part of the electrode array. Extensive fold-over may present as a second electrode array in the basal turn $[59,63]$. The basilar membrane may often be ruptured.

\section{Malposition in the tympanic cavity (Fig. 31)}

It the condition of an angulated entry to the basal turn, e.g., in case of CHARGE syndrome, the electrode array may not enter the basal turn and remains in the tympanic cavity near the round window niche [5]. Revision

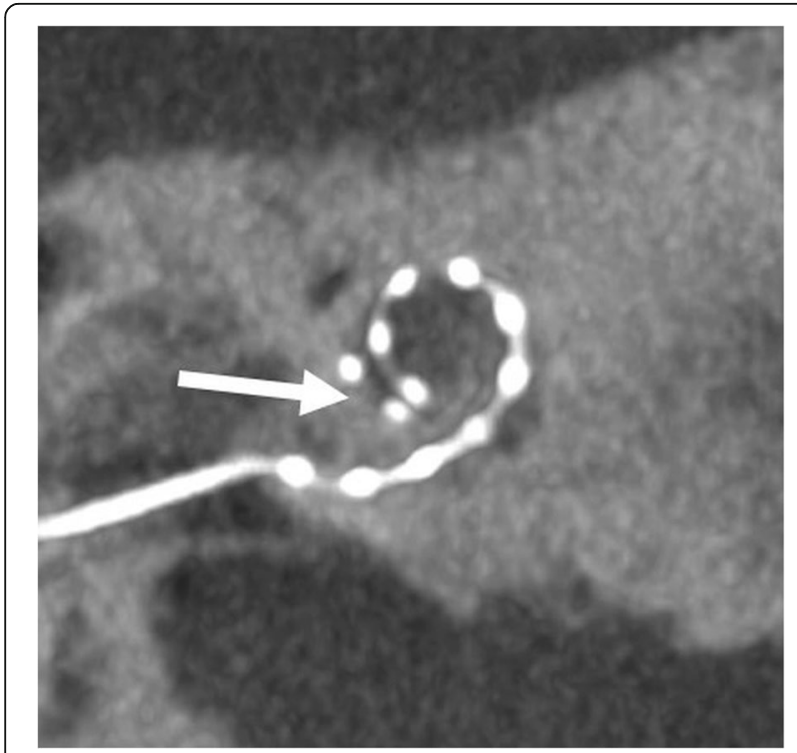

Fig. 29 A 66-year-old male patient, with tip fold-over. CBCT paraaxial maximum intensity projection image shows fold-over of the tip of the electrode in the cochlea (arrow) surgery for extracochlear electrode malposition should be performed by experienced surgeons.

\section{Malposition in the internal auditory canal (Fig. 32)}

The electrode array enters into the internal auditory canal or may form a more basal slope within the internal auditory canal. The condition of an incomplete partition type III is a risk factor, since there is no bony separation between cochlea and internal auditory canal $[69,70]$.

Malposition in vestibulum and semi-circular canals (Fig. 33) The electrode array may enter the vestibulum or semicircular canals in small round windows in children, or,

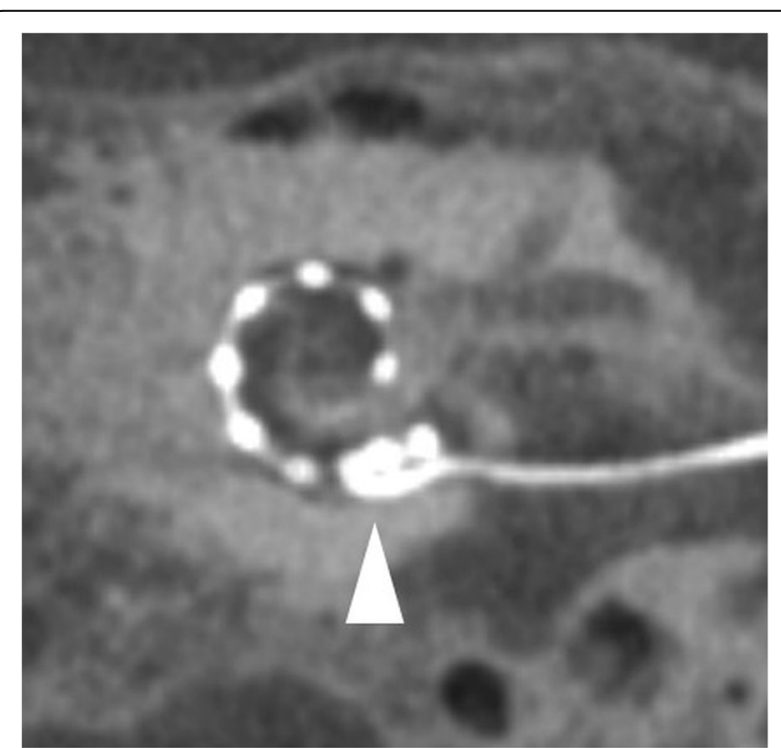

Fig. 30 A 55-year-old female patient, with basal fold-over. CBCT paraaxial maximum intensity projection image shows fold-over of the basal part of the electrode within the cochlea (arrowhead) 


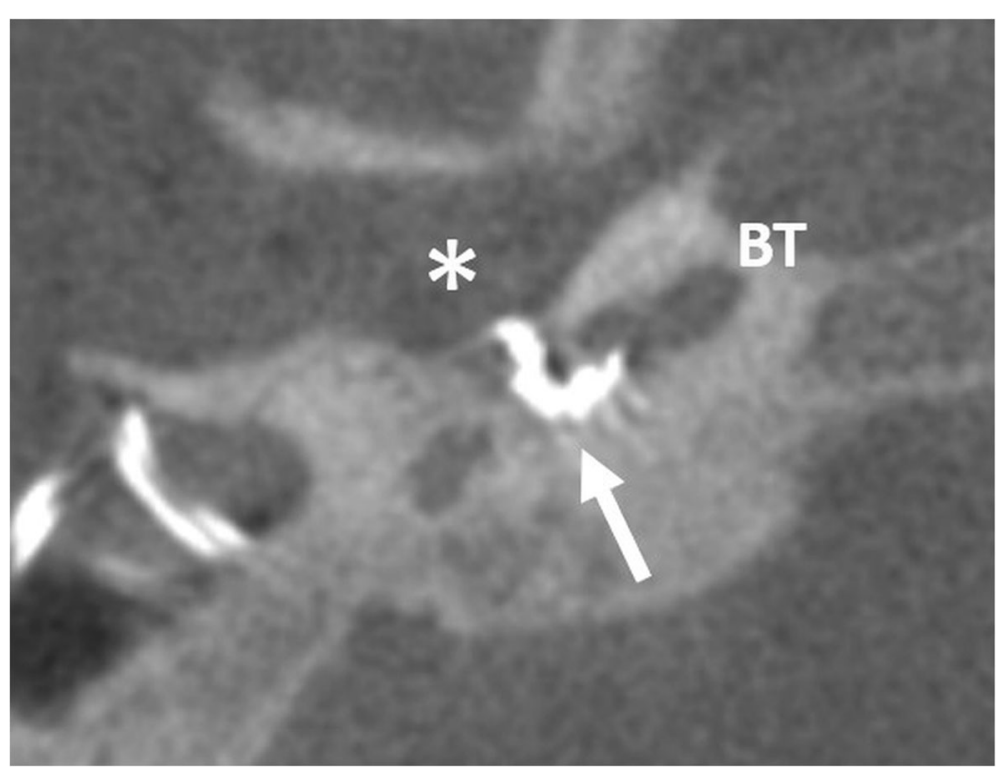

Fig. 31 A 13-year-old female patient, with CHARGE syndrome and malposition of the electrode in the tympanic cavity (asterisk). CBCT axial image shows the apical part of the electrode array (arrow) not passing the angled entry of the round window into the basal turn (BT)

in the condition of an anteriorized facial nerve, because there is an awkward insertion angle for the electrode array via the retro-facial route [71].

\section{Canal of the internal carotid artery or Eustachian tube}

Extracochlear electrode array placements like placement in the canal of the internal carotid artery or the Eustachian tube have been very rarely reported in the literature $[49,72]$.

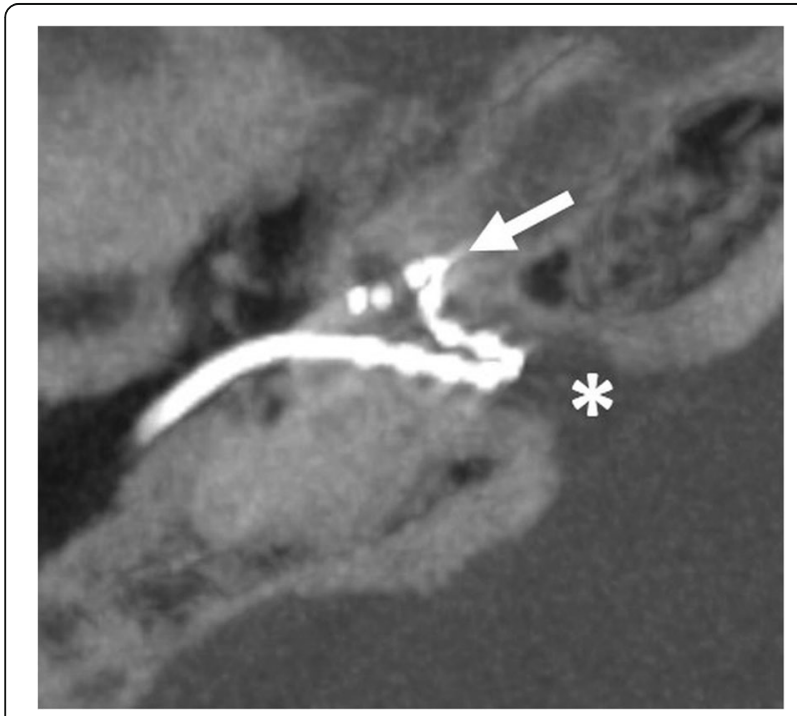

Fig. 32 A 20-year-old male patient, with incomplete partition type III and malposition of the electrode in the internal auditory canal. CBCT paraaxial maximum intensity projection image shows part of the electrode array in the basal turn (arrow), but the rest of the electrode forming a slope within the internal auditory canal (asterisk)

\section{Late complications}

Late complications occur after the acute post-operative period.

\section{Electrode migration (Fig. 34)}

An electrode array may migrate because of loss of support of the electrode lead, micro-movements in the soft tissue cover of the radical cavity, or a tension that pushes the electrode back [14]. Perimodiolar electrodes are affected less frequently and to a lower extent than lateral wall electrodes [73]. Minor migration may be asymptomatic or show a gradual increase in the impedance values in the basal electrodes [44, 74, 75]. Major back extrusion can lead to complete hearing loss.

\section{Flap complications (Fig. 35)}

Subcutaneous ulcer, infection, and wound dehiscence may occur at the implanted area of the magnet $[14,76]$. Flap necrosis is the result of postsurgical malperfusion. Surgical revision is required. Local trauma may result in hematoma and magnet migration [77].

\section{Bacterial labyrinthitis, otitis media, and cholesteatoma}

Bacterial labyrinthitis may be secondary to the spread of middle ear flora into the cochlea. Otitis media and mastoiditis are more frequently observed in children. Cholesteatoma may occur after the inclusion of epithelial cells into the tympanic cavity $[77,78]$.

\section{Fibrosis and delayed neural injury}

Surgical trauma, foreign body tissue response, or disruption of any soft tissue or venous structure of scala 

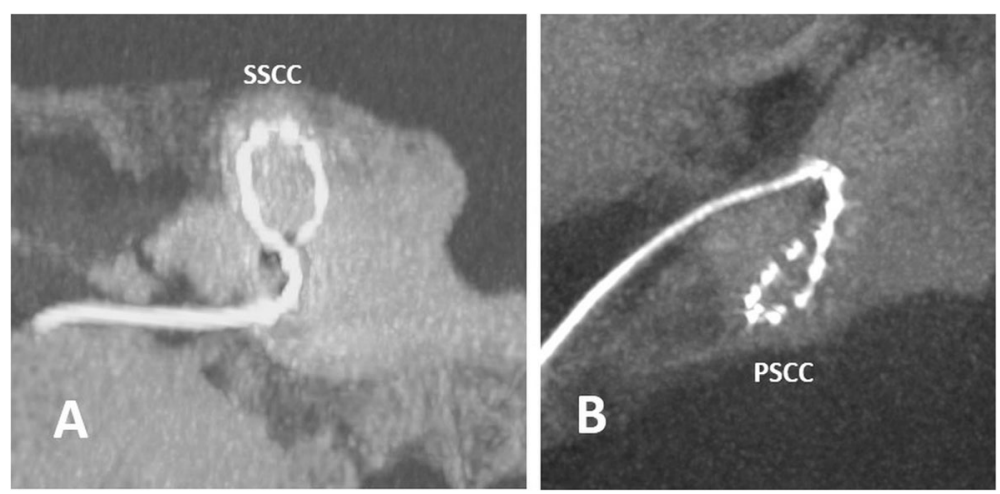

Fig. 33 a A 86-year-old male patient, with immediate postoperative nausea. CBCT paracoronal maximum intensity projection image shows the malposition of the electrode in the superior semi-circular canal (SSCC). b A 20-year-old male patient with asymptomatic malposition of the electrode in the posterior semi-circular canal (PSCC) on CBCT paraaxial maximum intensity projection image

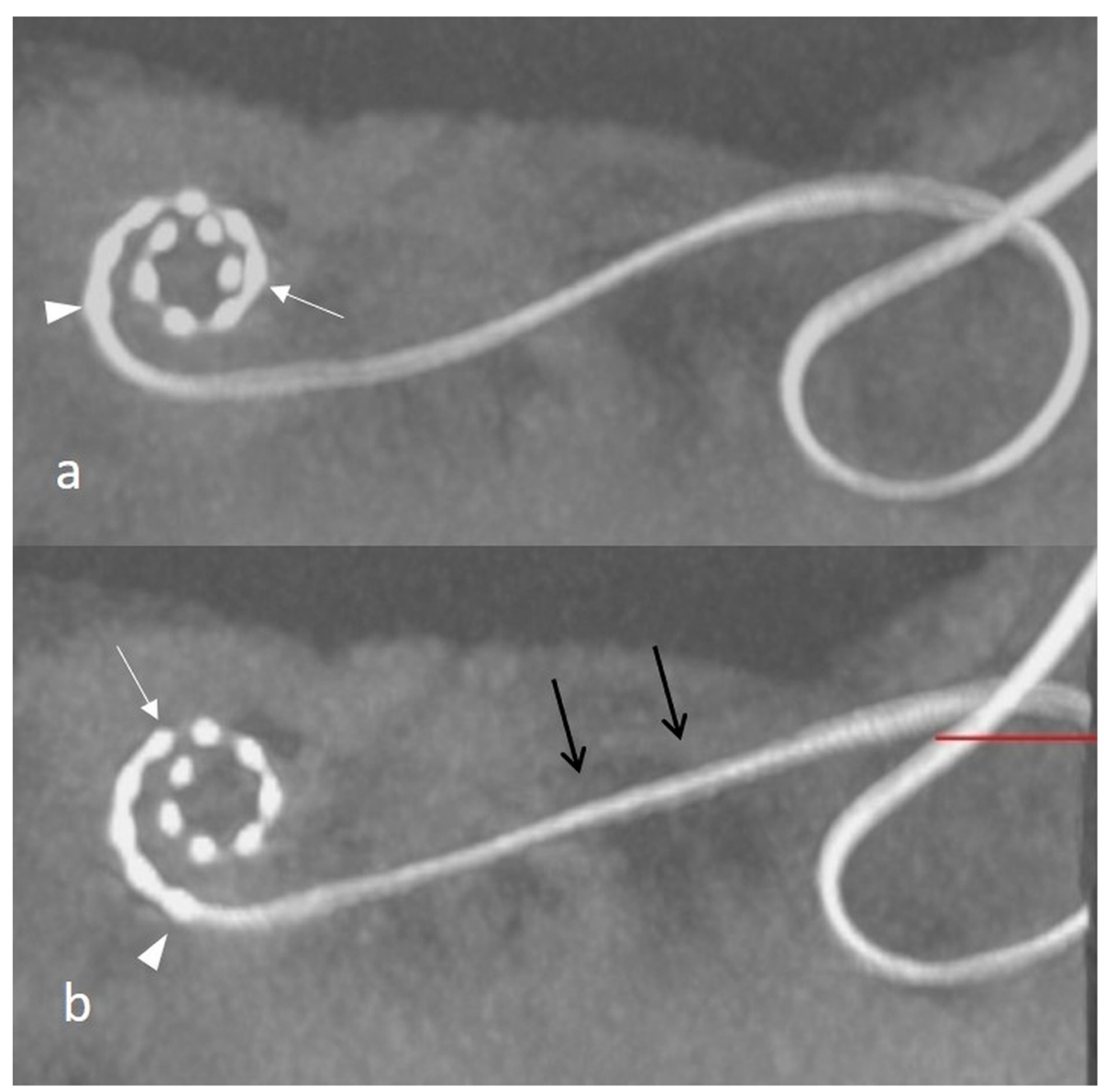

Fig. 34 A 53-year-old male patient, with a complete malfunction of the $\mathrm{Cl}$ and pain 3 months after $\mathrm{Cl}$ surgery. CBCT paraaxial maximum intensity projection image shows initial overinsertion of the electrode array (a). The control scan shows back extrusion of the electrode array with migrated positions of the electrode tip (arrow) and basal electrode element (arrowhead) and straightened electrode array (black arrows) in the mastoidectomy cave (b) 


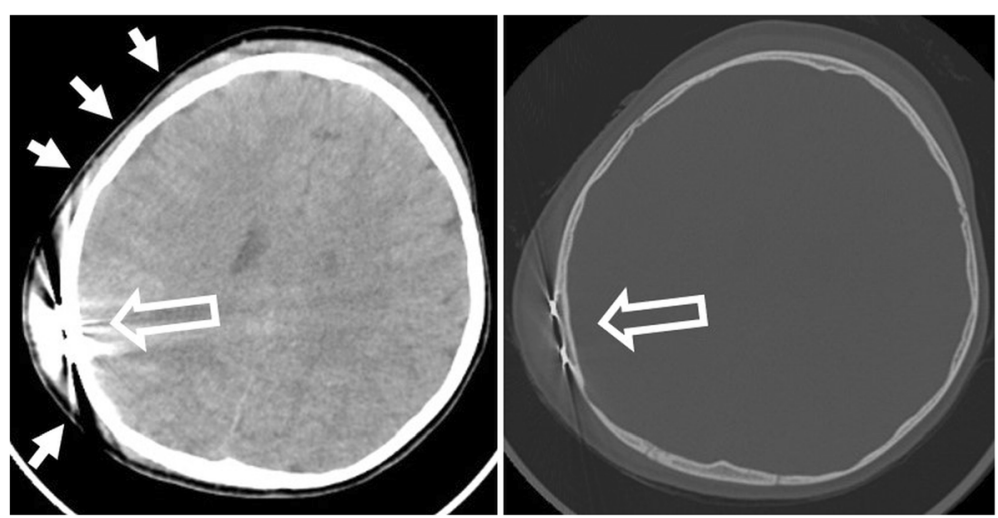

Fig. 35 A 4-year-old male patient, with pain and insufficient hold of the speech processor after running into his brother. CT axial soft kernel image (left image) shows marked hematoma (arrows) in the skin at the frontal bone and temporal bone around the implanted magnet (hollow arrow). No intracranial bleeding. CT bone kernel axial image (right image) shows intact bone. The magnet is in the correct position

tympani during insertion may induce intracochlear fibrosis [79]. The build-up of fibrosis and around the electrode over time will potentially impact or form a connection to the spiral ligament and basilar membrane, which will result in mechanical impedance with reduction or complete loss of hearing over time [80]. Delayed neural injury is explained by a molecular activation of apoptopic pathways by the insertion trauma and leads to continuous worsening of hearing [78].

\section{Conclusions}

CI candidates need a thorough pre-operative imaging for diagnosis and classification of inner ear malformations and to identify any other abnormality in the temporal bone. HRCT and MRI are complementary and both image modalities are useful in patients with a history of meningitis, severe middle ear disease, and dysmorphic syndromes. Important contraindications such as aplasia and labyrinth sclerosis need to be ruled out. Implant surgeons need to be informed about any anatomical findings that may have an influence on the surgical procedure. After surgery, the position of the electrode can be evaluated using CBCT or HRCT. Scalar dislocation, cochlear dislocation, electrode fold, and malposition should be reported and may have important consequences for the patient, such as refined tuning or revision surgery.

\section{Abbreviations}

2TL: Two-turn length; 3D-CISS: Three-dimensional constructive interference in steady-state; CBCT: Cone beam computed tomography; CDL: Cochlear duct length; Cl: Cochlear implant; HRCT: High-resolution computed tomography; MRI: Magnetic resonance imaging; Non-EPI DWI: Non-echo-planar imaging diffusion-weighted imaging; SNHL: Sensorineural hearing loss

\section{Acknowledgements}

The authors like to express their sincere gratitude to Erich Schmutzhard for editing the manuscript.
Funding information

There was no funding for this educational pictorial review.

\section{Authors' contributions}

Each author has made a substantial contribution to this manuscript: Gerlig Widmann: idea and concept of the work, analysis, and draft of the work.

Daniel Dejaco: acquisition of data. Anna Luger: acquisition of data. Joachim Schmutzhard: acquisition of data, substantively revised the data. All authors have approved the submitted version. All authors have agreed both to be personally accountable for the author's own contributions and ensure that questions related to the accuracy or integrity of any part of the work, even ones in which the author was not personally involved, are appropriately investigated, resolved, and the resolution documented in the literature.

Availability of data and materials

The data and image material were selected from the PACS-archive of our university hospital.

Ethics approval and consent to participate

Ethical approval and consent to participate was not needed for this educational pictorial review.

\section{Consent for publication}

Ethical approval and consent to participate was not needed for this educational pictorial review.

\section{Competing interests}

JS has an active scientific grant with the MedEL Company.

All other authors declare that they do not have any competing interests related to this article.

\section{Author details}

'Department of Radiology, Medical University of Innsbruck, Anichstr. 35, A-6020 Innsbruck, Austria. '2Department of Otorhinolaryngology-Head and Neck Surgery, Medical University of Innsbruck, Innsbruck, Austria.

Received: 8 June 2020 Accepted: 21 July 2020

Published online: 15 August 2020

\section{References}

1. Deep N, Dowling E, Jethanamest D, Carlson M (2018) Cochlear implantation: an overview. J Neurol Surg Part B Skull Base 80:169-177 https://doi.org/10. 1055/s-0038-1669411

2. Carlson ML, Sladen DP, Gurgel RK, Tombers NM, Lohse CM, Driscoll CL (2018) Survey of the American Neurotology Society on cochlear implantation: part 1, candidacy assessment and expanding indications. Otol Neurotol 39:e12-e19 https://doi.org/10.1097/MAO.0000000000001632

3. Vesseur A, Free R, Snels C et al (2018) Hearing restoration in cochlear nerve deficiency: the choice between cochlear implant or auditory brainstem 
implant, a meta-analysis. Otol Neurotol 39:428-437 https://doi.org/10.1097/ MAO.0000000000001727

4. Peng KA, Kuan EC, Hagan S, Wilkinson EP, Miller ME (2017) Cochlear nerve aplasia and hypoplasia: predictors of cochlear implant success. Otolaryngol Head Neck Surg 157:392-400

5. Birman CS, Brew JA, Gibson WPR, Elliott EJ (2015) CHARGE syndrome and cochlear implantation: difficulties and outcomes in the paediatric population. Int J Pediatr Otorhinolaryngol 79:487-492 https://doi.org/10. 1016/j.jporl.2015.01.004

6. Amin N, Sethukumar P, Pai I, Rajput K, Nash R (2019) Systematic review of cochlear implantation in CHARGE syndrome. Cochlear Implants Int 20:266$280 \mathrm{https}: / /$ doi.org/10.1080/14670100.2019.1634857

7. Birman CS, Elliott EJ, Gibson WPR (2012) Pediatric cochlear implants: additional disabilities prevalence, risk factors, and effect on language outcomes. Otol Neurotol 33:1347-1352 https://doi.org/10.1097/MAO 0b013e31826939cc

8. Berrettini S, Baggiani A, Bruschini L et al (2011) Systematic review of the literature on the clinical effectiveness of the cochlear implant procedure in adult patients. Acta Otorhinolaryngol Ital 31:299-310

9. Hellingman CA, Dunnebier EA (2009) Cochlear implantation in patients with acute or chronic middle ear infectious disease: a review of the literature. Eur Arch Otorhinolaryngol 266:171-176

10. Sennaroglu L (2010) Cochlear implantation in inner ear Malformations - A review article. Cochlear Implants Int 11:4-41

11. Sennaroğlu L, Bajin MD (2017) Classification and current management of inner ear malformations. Balkan Med J 34:397-411 https://doi.org/10.4274/ balkanmedj.2017.0367

12. Aldhafeeri AM, Alsanosi AA (2017) Management of surgical difficulties during cochlear implant with inner ear anomalies. Int J Pediatr Otorhinolaryngol 92:45-49 https://doi.org/10.1016/j.jporl.2016.11.001

13. Marsot-Dupuch K, Meyer B (2001) Cochlear implant assessment: imaging issues. Eur J Radiol 40:119-132

14. Gheorghe DC, Zamfir-Chiru-Anton A (2015) Complications in cochlear implant surgery. J Med Life 8:329-332 https://doi.org/10.1055/s-1999-8753

15. Yigit O, Kalaycik Ertugay C, Yasak AG, Araz Server E (2019) Which imaging modality in cochlear implant candidates? Eur Arch Otorhinolaryngol 276: 1307-1311 https://doi.org/10.1007/s00405-019-05349-0

16. Digge P, Solanki RN, Shah DC, Vishwakarma R, Kumar S (2016) Imaging modality of choice for pre-operative cochlear imaging: HRCT vs. MRI temporal bone. J Clin Diagn Res 10:10-13 https://doi.org/10.7860/JCDR/ 2016/18033.8592

17. Wu W-J, He X-B, Tan L-H et al (2015) Imaging assessment of profound sensorineural deafness with inner ear anatomical abnormalities. J Otol 10: 29-38 https://doi.org/10.1016/j.joto.2015.07.005

18. Koch RW, Ladak HM, Elfarnawany M, Agrawal SK (2017) Measuring cochlear duct length - a historical analysis of methods and results. J Otolaryngol Head Neck Surg 46:19

19. Alexiades G, Dhanasingh A, Jolly C (2015) Method to estimate the complete and two-turn cochlear duct length. Otol Neurotol 36:904-907 https://doi. org/10.1097/MAO.0000000000000620

20. Parry DA, Booth T, Roland PS (2005) Advantages of magnetic resonance imaging over computed tomography in pre-operative evaluation of pediatric cochlear implant candidates. Otol Neurotol 26:976-982 https://doi. org/10.1097/01.mao.0000185049.61770.da

21. Dhanasingh A, Jolly C (2017) An overview of cochlear implant electrode array designs. Hear Res 356:93-103 https://doi.org/10.1016/j.heares.2017.10. 005

22. Mierzwiński J, Van Den Heuvel E, Fishman AJ, Rivera AL, Haber K, Skrivan J (2018) Application of "banana cochleostomy" and looped electrode insertion for cochlear implantation in children with common cavity malformation and cystic forms of cochlear hypoplasia. Int J Pediatr Otorhinolaryngol 112:16-23 https://doi.org/10.1016/j.jporl.2018.06.018

23. Gaur SK, Dutt SN, Kumar A (2019) The common cavity vs incomplete partition type I conundrum: decision making and management with the cochlear implant form electrode. Cochlear Implants Int 20:158-163 https:/ doi.org/10.1080/14670100.2019.1582852

24. Beltrame MA, Birman CS, Cervera Escario J et al (2013) Common cavity and custom-made electrodes: speech perception and audiological performance of children with common cavity implanted with a custom-made MED-EL electrode. Int J Pediatr Otorhinolaryngol 77:1237-1243 https://doi.org/10. 1016/j.jporl.2013.04.008
25. Eftekharian A, Eftekharian K, Mokari N, Fazel M (2019) Cochlear implantation in incomplete partition type I. Eur Arch Otorhinolaryngol 276:2763-2768 https://doi.org/10.1007/s00405-019-05534-1

26. Berrettini S, Forli F, De Vito A, Bruschini L, Quaranta N (2013) Cochlear implant in incomplete partition type I. Acta Otorhinolaryngol Ital 33:56-62

27. Incesulu A, Adapinar B, Kecik C (2008) Cochlear implantation in cases with incomplete partition type III (X-linked anomaly). Eur Arch Otorhinolaryngol 265:1425-1430 https://doi.org/10.1007/s00405-008-0614-z

28. Sennaroğlu L, Bajin MD (2018) Incomplete partition type III: a rare and difficult cochlear implant surgical indication. Auris Nasus Larynx 45:26-32 https://doi.org/10.1016/j.anl.2017.02.006

29. Bajin MD, Pamuk AE, Pamuk G, Özgen B, Sennaroglu L (2018) The association between modiolar base anomalies and intraoperative cerebrospinal fluid leakage in patients with incomplete partition type-ii anomaly: a classification system and presentation of 73 cases. Otol Neurotol 39:e538-e542 https://doi.org/10.1097/MAO.0000000000001871

30. Sennaroğlu L, Atay G, Bajin MD (2014) A new cochlear implant electrode with a "cork"-type stopper for inner ear malformations. Auris Nasus Larynx 41:331-336 https://doi.org/10.1016/j.anl.2013.12.011

31. Connor SEJ, Dudau C, Pai I, Gaganasiou M (2019) Is CT or MRI the optimal imaging investigation for the diagnosis of large vestibular aqueduct syndrome and large endolymphatic sac anomaly? Eur Arch Otorhinolaryngol 276:693-702 https://doi.org/10.1007/s00405-019-05279-x

32. Clarós P, Fokouo JVF, Clarós A (2017) Cochlear implantation in patients with enlarged vestibular aqueduct. A case series with literature review. Cochlear Implants Int 18:125-129 https://doi.org/10.1080/14670100.2016. 1268754

33. Dewan K, Wippold FJ, Lieu JEC (2009) Enlarged vestibular aqueduct in pediatric sensorineural hearing loss. Otolaryngol Head Neck Surg 140:552558 https://doi.org/10.1016/j.otohns.2008.12.035

34. Palabiyik FB, Hacikurt K, Yazici Z (2017) Facial nerve anomalies in paediatric cochlear implant candidates: radiological evaluation. J Laryngol Otol 131: 26-31 https://doi.org/10.1017/S0022215116009555

35. Telmesani LM, Alrammah MK (2017) Telmesani radiological classification of the location of the vertical segment of the facial nerve: impact on surgical approach in cochlear implant surgery. Otol Neurotol 38:e335-e338 https:/ doi.org/10.1097/MAO.0000000000001547

36. Dejaco D, Prejban D, Fischer $N$ et al (2018) Successful cochlear implantation of a split electrode array in a patient with far-advanced otosclerosis assisted by electromagnetic navigation: a case report. Otol Neurotol 39:e532-e537 https://doi.org/10.1097/MAO.0000000000001845

37. Yi JS, Lim HW, Kang BC, Park SY, Park HJ, Lee KS (2013) Proportion of bony cochlear nerve canal anomalies in unilateral sensorineural hearing loss in children. Int J Pediatr Otorhinolaryngol 77:530-533 https://doi.org/10.1016/j. ijporl.2012.12.031

38. Tahir E, Bajin MD, Atay G, Mocan BÖ (2017) Bony cochlear nerve canal and internal auditory canal measures predict cochlear nerve status. J Laryngol Otol 131:676-683 https://doi.org/10.1017/S0022215117001141

39. Giesemann AM, Kontorinis G, Jan Z, Lenarz T, Lanfermann H, Goetz F (2012) The vestibulocochlear nerve: aplasia and hypoplasia in combination with inner ear malformations. Eur Radiol 22:519-524 https://doi.org/10.1007/ s00330-011-2287-z

40. Vashishth A, Fulcheri A, Prasad SC et al (2017) Cochlear implantation in cochlear ossification. Otol Neurotol 39(1) https://doi.org/10.1097/mao. 0000000000001613

41. Rak K, Völker J, Schendzielorz P et al (2018) Cochlear implantation in chronic otitis media: investigation of long-term speech comprehension and rate of complications. Otol Neurotol 39:e979-e984 https://doi.org/10.1097/MAO. 0000000000002026

42. Vashishth A, Fulcheri A, Prasad SC, Dandinarasaiah M, Caruso A, Sanna M (2018) Cochlear implantation in chronic otitis media with cholesteatoma and open cavities: long-term surgical outcomes. Otol Neurotol 39:45-53 https://doi.org/10.1097/MAO.0000000000001624

43. Jain R, Mukherji SK (2003) Cochlear implant failure: imaging evaluation of the electrode course. Clin Radiol 58:288-293

44. Holder JT, Kessler DM, Noble JH, Gifford RH, Labadie RF (2018) Prevalence of extracochlear electrodes: computerized tomography scans, cochlear implant maps, and operative reports. Otol Neurotol 39:e325-e331 https://doi.org/10. 1097/MAO.0000000000001818

45. Ruivo J, Mermuys K, Bacher K, Kuhweide R, Offeciers E, Casselman JW (2009) Cone beam computed tomography, a low-dose imaging technique in the 
post-operative assessment of cochlear implantation. Otol Neurotol 30:299-303 https://doi.org/10.1097/MAO.0b013e31819679f9

46. Marx M, Risi F, Escudé B et al (2014) Reliability of cone beam computed tomography in scalar localization of the electrode array: a radio histological study. Eur Arch Otorhinolaryngol 271:673-679 https://doi.org/10.1007/ s00405-013-2448-6

47. Widmann G, Fasser M, Schullian P et al (2012) Substantial dose reduction in modern multi-slice spiral computed tomography (MSCT)-guided craniofacial and skull base surgery. Rofo 184:136-142 https://doi.org/10.1055/s-00311281971

48. Grandmougin A, Bakour O, Villani N et al (2020) Metal artifact reduction for small metal implants on $\mathrm{CT}$ : which image reconstruction algorithm performs better? Eur J Radiol 127 https://doi.org/10.1016/j.ejrad.2020.108970

49. Ying YLM, Lin JW, Oghalai JS, Williamson RA (2013) Cochlear implant electrode misplacement: incidence, evaluation, and management. Laryngoscope 123:757-766 https://doi.org/10.1002/lary.23665

50. Fischer N, Pinggera L, Weichbold V, Dejaco D, Schmutzhard J, Widmann G (2015) Radiologic and functional evaluation of electrode dislocation from the scala tympani to the scala vestibuli in patients with cochlear implants. AJNR Am J Neuroradiol 36:372-377 https://doi.org/10.3174/ajnr.A4189

51. Richard C, Fayad JN, Doherty J, Linthicum FH (2012) Round window versus cochleostomy technique in cochlear implantation: histologic findings. Otol Neurotol 33:1181-1187 https://doi.org/10.1097/MAO.0b013e318263d56d

52. Van de Heyning P, Adunka O, Arauz SL et al (2013) Standards of practice in the field of hearing implants. Cochlear Implants Int 14:S1-S5 https://doi.org/ 10.1179/1467010013z.00000000093

53. O'Connell BP, Hunter JB, Wanna GB (2016) The importance of electrode location in cochlear implantation. Laryngoscope Investig Otolaryngol 1:169174 https://doi.org/10.1002/lio2.42

54. Roland JT, Coelho DH, Pantelides H, Waltzman SB (2008) Partial and doublearray implantation of the ossified cochlea. Otol Neurotol 29:1068-1075

55. Senn P, Rostetter C, Arnold A et al (2012) Retrograde cochlear implantation in postmeningitic basal turn ossification. Laryngoscope 122:2043-2050 https://doi.org/10.1002/lary.23397

56. Martins GD, Brito Neto RV, Tsuji RK, Gebrim EM, Bento RF (2015) Evaluation of intracochlear trauma caused by insertion of cochlear implant electrode arrays through different quadrants of the round window. Biomed Res Int 2015:236364 https://doi.org/10.1155/2015/236364

57. Eshraghi AA, Yang NW, Balkany TJ (2003) Comparative study of cochlear damage with three perimodiolar electrode designs. Laryngoscope 113:415419 https://doi.org/10.1097/00005537-200303000-00005

58. De Seta D, Mancini P, Russo FY et al (2016) 3D curved multiplanar cone beam ct reconstruction for intracochlear position assessment of straight electrodes array. A temporal bone and clinical study. Acta Otorhinolaryngol Ital 36:499-505 https://doi.org/10.14639/0392-100X-1279

59. Hoskison E, Mitchell S, Coulson C (2017) Systematic review: radiological and histological evidence of cochlear implant insertion trauma in adult patients. Cochlear Implants Int 18:192-197 https://doi.org/10.1080/14670100.2017. 1330735

60. Kamakura T, Nadol JB (2016) Correlation between word recognition score and intracochlear new bone and fibrous tissue after cochlear implantation in the human. Hear Res 339:132-141 https://doi.org/10.1016/j.heares.2016. 06.015

61. Li PMMC, Somdas MA, Eddington DK, Nadol JB (2007) Analysis of intracochlear new bone and fibrous tissue formation in human subjects with cochlear implants. Ann Otol Rhinol Laryngol 116:731-738 https://doi. org/10.1177/000348940711601004

62. Wanna GB, Noble JH, Carlson ML et al (2014) Impact of electrode design and surgical approach on scalar location and cochlear implant outcomes. Laryngoscope 124:S1-S7 https://doi.org/10.1002/lary.24728

63. Dhanasingh A, Jolly C (2019) Review on cochlear implant electrode array tip fold-over and scalar deviation. J Otol 14:94-100

64. Vashishth A, Fulcheri A, Guida M, Caruso A, Sanna M (2018) Incomplete and false tract insertions in cochlear implantation: retrospective review of surgical and auditory outcomes. Eur Arch Otorhinolaryngol 275:1059-1068 https://doi.org/10.1007/s00405-018-4924-5

65. Ishiyama A, Risi F, Boyd P (2020) Potential insertion complications with cochlear implant electrodes. Cochlear Implants Int 21:206-219 https://doi. org/10.1080/14670100.2020.1730066
66. Gabrielpillai J, Burck I, Baumann U, Stöver T, Helbig S (2018) Incidence for tip foldover during cochlear implantation. Otol Neurotol 39:1115-1121 https://doi.org/10.1097/MAO.0000000000001915

67. Ramos-Macias A, De Miguel AR, Falcon-González JC (2017) Mechanisms of electrode fold-over in cochlear implant surgery when using a flexible and slim perimodiolar electrode array. Acta Otolaryngol 137:1129-1135 https:// doi.org/10.1080/00016489.2016.1271449

68. Zuniga MG, Rivas A, Hedley-Williams A et al (2017) Tip fold-over in cochlear implantation: case series. Otology and Neurotology. Lippincott Williams and Wilkins, 199-206

69. Mehanna AM, Gamaleldin OA, Fathalla MF (2019) The misplaced cochlear implant electrode array. Int J Pediatr Otorhinolaryngol 117:96-104 https:// doi.org/10.1016/j.ijporl.2018.11.027

70. Todt I, Rademacher G, Ernst A (2013) Identification and revision of a displaced cochlear implant electrode in the internal auditory canal. Cochlear Implants Int 14:236-239 https://doi.org/10.1179/1754762812y.0000000015

71. Sun JQ, Sun JW, Hou XY, Bie YZ, Chen JW (2014) Electrode array misplacement into the superior semicircular canal: as a rare complication of cochlear implantation. Int J Pediatr Otorhinolaryngol 78:1537-1540 https:// doi.org/10.1016/j.jporl.2014.06.033

72. Gözen ED, Tevetoğlu F, Yener HM et al (2019) Extra-cochlear insertion in cochlear implantation: a potentially disastrous condition. J Int Adv Otol 15: 358-363 https://doi.org/10.5152/iao.2019.6492

73. Mittmann P, Rademacher G, Mutze S, Ernst A, Todt I (2015) Electrode migration in patients with perimodiolar cochlear implant electrodes. Audiol Neurotol 20:349-353 https://doi.org/10.1159/000435873

74. Dietz A, Wennström M, Lehtimäki A, Löppönen H, Valtonen H (2016) Electrode migration after cochlear implant surgery: more common than expected? Eur Arch Otorhinolaryngol 273:1411-1418 https://doi.org/10. 1007/s00405-015-3716-4

75. Zawawi F, Cushing SL, James AL, Gordon KA, Papsin BC (2019) Extrusion of straight cochlear implant electrodes may be diminished by proximal fixation. Int J Pediatr Otorhinolaryngol 116:164-167 https://doi.org/10.1016/j. ijporl.2018.10.031

76. Grover M, Sharma S, Kataria T, Samdani S, Agarwal S, Singh SN (2018) Soft tissue reactions following cochlear implantation. Eur Arch Otorhinolaryngol 0:0 https://doi.org/10.1007/s00405-018-5233-8

77. Dagkiran M, Tarkan O, Surmelioglu O et al (2020) Management of complications in 1452 pediatric and adult cochlear implantations. Turk Arch Otorhinolaryngol 58:16-23 https://doi.org/10.5152/tao.2020.5025

78. Farinetti A, Gharbia DB, Mancini J, Roman S, Nicollas R, Triglia JM (2014) Cochlear implant complications in 403 patients: comparative study of adults and children and review of the literature. Eur Ann Otorhinolaryngol Head Neck Dis 131:177-182 https://doi.org/10.1016/j.anorl.2013.05.005

79. Roland PS, Wright CG (2006) Surgical aspects of cochlear implantation: mechanisms of insertional trauma. Adv Otorhinolaryngol 64:11-30

80. Fayad JN, Makarem AO, Linthicum FH (2009) Histopathologic assessment of fibrosis and new bone formation in implanted human temporal bones using 3D reconstruction. Otolaryngol Head Neck Surg 141:247-252 https:// doi.org/10.1016/j.otohns.2009.03.031

\section{Publisher's Note}

Springer Nature remains neutral with regard to jurisdictional claims in published maps and institutional affiliations. 